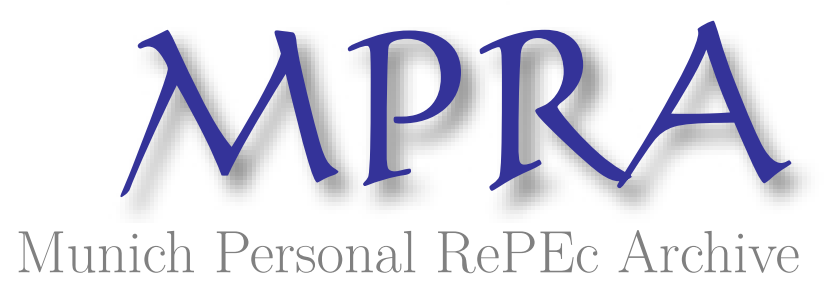

Structural heterogeneity or asymmetric shocks? Poland and the euro area through the lens of a two-country DSGE model

Kolasa, Marcin

National Bank of Poland

May 2008

Online at https://mpra.ub.uni-muenchen.de/8750/

MPRA Paper No. 8750, posted 14 May 2008 13:08 UTC 


\title{
Structural heterogeneity or asymmetric shocks? Poland and the euro area through the lens of a two-country DSGE model
}

\author{
Marcin Kolasa* \\ National Bank of Poland
}

May 14, 2008

\begin{abstract}
This paper presents a two-country model linking Poland and the euro area and applies it for assessment of heterogeneity across these two regions. Overall, our results can be seen as rather inconclusive about the differences in parameters describing agents' decision-making in Poland and in the euro area. On the contrary, we find strong evidence for heterogeneity in terms of volatility and synchronization of shocks hitting both economies. Our results may be viewed as a step towards estimating the costs of Poland's entry to the European Monetary Union, associated with giving up the monetary autonomy and losing benefits from stabilizing movements of the exchange rate.
\end{abstract}

\section{Introduction}

This paper presents an estimated two-country dynamic stochastic general equilibrium (DSGE) model for Poland and the euro area and applies it for assessing the degree of heterogeneity between these two regions. In particular, relative relevance of two sources of heterogeneity are examined: differences in structural parameters and asymmetry of shocks hitting the two economies.

While comparing a set of structural and stochastic characteristics of the Polish economy with those prevailing in the euro area seems to be an interesting task in itself, our research is additionally motivated by Poland's prospective entry to the European Monetary Union (EMU). A standard and well-known implication of the optimal currency area (OCA) theory is that asymmetric temporary shocks and asymmetric short-run response to common shocks weaken the case for a common currency, as being a member of a monetary union implies losing benefits form the monetary autonomy and stabilizing movements of the exchange rate. ${ }^{1}$ Consequently, identifying the main sources of heterogeneity between Poland and the euro area may be viewed as an important step towards assessing the costs of Poland's EMU-entry.

The structure of our model builds largely on the previous work in the new open economy macroeconomics (NOEM) literature, launched by the influential contribution by Obstfeld and Rogoff (1995). ${ }^{2}$ The choice of a particular setup of the workhorse model is always a task involving a great deal of subjectivity. Building a large and comprehensive model, with a large number of stochastic disturbances and rich propagation mechanisms, is a time-consuming task. Moreover, taking big and sophisticated models to the data is usually far from straightforward, if not impossible, given data availability. ${ }^{3}$ Needless to say, these kinds of constraints to

\footnotetext{
*E-mail: Marcin.Kolasa@mail.nbp.pl

${ }^{1}$ The classical reference is Mundell (1961), see also Tower and Willett (1976) for a summary of subsequent contributions. A modern reconsideration of the OCA theory can be found in Corsetti (2008).

${ }^{2}$ See also Obstfeld and Rogoff (2000). An extensive survey of the NOEM literature is provided by Lane (2001).

${ }^{3}$ Bergin (2003) was one of the first to estimate a NOEM model. Later contributions, with more complicated structure include de Walque and Wouters (2004) or Adolfson et al. (2005), both of which can be considered as open economy versions of the influential Smets and Wouters (2003) setup. Relatively large multi-country DSGE models are maintained at the IMF, the two most popular of which are Global Economic Model (Laxton and Pesenti, 2003) and Global Fiscal Model (Botman et al., 2006), see Botman et al. (2007) for an overview. However, these models are calibrated rather than estimated.
} 
empirical investigations are particularly severe for countries like Poland. The most relevant obstacles are short time series and scarcity of well-established stylized facts.

Taking into account these considerations, our strategy is to keep the size of the model relatively small, so that it is possible to estimate most of its important and not-easy-to-pin-down parameters, instead of resorting to calibrations. The small size has an additional advantage of increased clarity and operationality. The obvious limitation is a risk of neglecting potentially important mechanisms, relevant for the problem considered.

Given the main focus of the paper and our future research objectives, including examination of macroeconomic stabilization and shock propagation in alternative monetary and exchange rate regimes, we want to emphasize the following choices underlying our theoretical and empirical strategy. First, while keeping the main structure of our model relatively simple, we are less reductionist in those model components that are known to be of particular relevance for an appropriate description of the nominal side of the economy. This motivates the following choices: a two-sector setup allowing for 'home bias' in preferences, explicit modelling of distribution services for consumption goods and separating price-related nominal rigidities from those arising from the labour market. ${ }^{4}$ Second, we favour a structure enabling us to switch the model between flexible and fixed exchange rate regimes without the need to pin down any additional parameters. The complete asset market assumption is particularly useful in this respect. Third, as we want to focus on cyclical comovements between macrovariables in the two regions, we abstract from long-term trends in the data. This justifies several transformations of the observable variables, which we discuss in more detail in section $3{ }^{5}$

Our two-country model is driven by fourteen stochastic disturbances, seven for each economy. Innovations to the shocks are allowed to be correlated across countries. We estimate our model using Bayesian methods, which allow one to formalize the use of a priori beliefs in the estimation process. The merits of the Bayesian approach in fitting DSGE models are well-known. ${ }^{6}$ Two of these stand out as particularly important for our study. First, given short time series available, incorporating additional information is necessary to mitigate identification problems, which make the unconstrained maximum likelihood method unreliable or at least impractical. At the same time, the Bayesian approach allows one to avoid the other extreme strategy, i.e. pure calibration, the implementation of which is inhibited by lack of appropriate micro-evidence for Poland, helping one to pin down some of the structural parameters. Second, Bayesian estimation naturally leads to the comparison of models based on their fit to the data. This provides a useful platform for formal testing of various sources of heterogeneity across Poland and the euro area by comparing and validating unrestricted and several restricted versions of our model.

This paper is not the first one examining heterogeneity between economies in a multi-country DSGE setup. However, the previous studies usually focused on asymmetries between relatively closely related economies, using models which were probably too stylized to employ them for assessing the degree of asymmetry between a transition country like Poland and a highly integrated and developed club like the euro area. For instance, Jondeau and Sahuc (2005) examine heterogeneity between the three largest euro area economies using a stylized DSGE model, which abstracts from capital accumulation and wage rigidities. In a much richer setup, Pytlarczyk (2005) analyzes Germany within the euro area, but, similarly to Jondeau and Sahuc (2005), assumes that all goods are tradable. A separate treatment of tradable and nontradable goods is provided by Rabanal (2007), who focuses on Spain's links with the euro area. However, his model assumes the production function to be linear in labour and fully flexible wages. None of the above mentioned contributions includes the distributions sector for consumption goods.

Our main results can be summarized as follows. First, while some of the structural parameters (i.e. those describing microfounded decision mechanisms of the agents) in Poland and in the euro area seem to be somewhat different, relatively low precision of the estimates does not allow to draw any firm conclusions

\footnotetext{
${ }^{4}$ The importance of including non-traded goods in NOEM models was emphasised e.g. by Obstfeld and Rogoff (2000). The implications of home bias in goods preferences for exchange rate dynamics are demonstrated in Warnock (1998) and Benigno and Thoenissen (2003). The introduction of the distribution sector in NOEM models is largely due to Erceg and Levin (1996). Rabanal and Rubio-Ramirez (2005) argue that models with both staggered price nad wage setting dominate models with only one type of rigidity.

${ }^{5}$ While abstracting from long-run interrelations between macrovariables might generally be seen as a clear disadvantage, it has an important merit while working with data for a transition economy. As demonstrated by Rabanal (2007), imposing dogmatic long-run restrictions in a stylized model estimated for a country undergoing structural shifts may sizably worsen its fit to the data, including the ability to replicate the key second moments.

${ }^{6} \mathrm{~A}$ comprehensive overview of Bayesian methods used for estimation of DSGE models is provided by An and Schorfheide (2007). See also Fernandez-Villaverde and Rubio-Ramirez (2004) or Lubik and Schorfheide (2006).
} 
in this respect. As regards the monetary policy feedback rules, interest rate smoothing seems to be more important in the euro area than in Poland, however, the model allowing for different parametrization of the Taylor rules across countries does not clearly outperform the one assuming homogeneity. While we do not find any strong evidence for heterogeneity in terms of inertia of the stochastic disturbances, their volatility is significantly higher in Poland. Finally, our results suggest that structural shocks are rather weakly correlated across Poland and the euro area.

The rest of the paper is organized as follows. Section 2 presents the structure of our two country model. Section 3 discusses data issues. The empirical strategy and estimation results are presented in section 4 . Section 5 evaluates the dynamic properties of the model. Formal tests of heterogeneity between Poland and the euro area are performed and discussed in section 6 . Section 7 concludes.

\section{Structure of the model}

There are two countries in the world: Home $(H)$ and Foreign $(F)$. Each country is inhabited by a continuum of infinite-lived consumers, distributed over the intervals of $[0, n]$ and $[n, 1]$, respectively. Both countries produce a continuum of differentiated tradable goods, indexed on the interval $[0, n]$ in the Home economy and $[n, 1]$ in the Foreign economy. Each country produces also an array of nontradable goods, distributed over the same intervals as tradable goods. Since the general setup of the Foreign country is similar to that for the Home economy, in what follows we focus on the exposition for the latter. To the extent needed, variables and parameters referring to foreign agents are marked with an asterisk.

\subsection{Households}

Households in a given country are assumed to be homogenous, i.e. they have the same preferences and endowments. Households provide labour services and rent capital to domestic firms. Each household has access to complete markets for state-contingent claims, which implies that any idiosyncratic shocks among the households do not result in heterogeneity of their behaviour. Hence, we can focus on the optimization problem of a representative household for a given country.

A typical household $j$ in the Home country maximizes the following lifetime utility function:

$$
U_{t}(j)=E_{t} \sum_{k=0}^{\infty} \beta^{k}\left[\frac{\varepsilon_{d, t+k}}{1-\sigma}\left(C_{t+k}(j)-h C_{t-1}\right)^{1-\sigma}-\frac{\varepsilon_{l, t+k}}{1+\varphi} L_{t+k}(j)^{1+\varphi}\right]
$$

where $E_{t}$ denotes the expectation operator conditional on information available at time $t, \beta$ is the discount rate, $\sigma$ is the inverse of the elasticity of intertemporal substitution, $h$ is the external habit persistence parameter, $\varphi$ is the inverse of the Frisch elasticity of labour supply. The instantaneous utility is thus a function of a consumption bundle $C_{t}$, to be defined below, and labour effort $L_{t}$.

The maximization of (1) is subject to a sequence of intertemporal budget constraints of the form:

$$
\begin{aligned}
& P_{C, t} C_{t}(j)+P_{I, t} I_{t}(j)+E_{t}\left\{\Upsilon_{t, t+1} B_{t+1}(j)\right\} \\
= & B_{t}(j)+W_{t}(j) L_{t}(j)+R_{t}^{K} K_{t}(j)+\Pi_{H, t}(j)+\Pi_{N, t}(j)+T_{t}(j)
\end{aligned}
$$

where $P_{C, t}$ denotes the price of the consumption bundle $C_{t}, P_{I, t}$ is the price of investment goods $I_{t}, B_{t+1}$ is the nominal payoff in period $t+1$ of the portfolio held at the end of period $t, W_{t}$ is the nominal wage, $R_{t}^{K}$ denotes household's income from renting capital $K_{t}, \Pi_{H, t}(j)$ and $\Pi_{N, t}(j)$ are dividends from tradable and nontradable goods producers, respectively, while $T_{t}$ stands for lump sum government transfers net of lump sum taxes. $\Upsilon_{t, t+1}$ is the stochastic discount factor for nominal payoffs, such that $E_{t} \Upsilon_{t, t+1}=R_{t}^{-1}$, where $R_{t}$ is the gross return on a riskless one-period bond. There are two shocks to instantaneous utility, common to all households in the home country: consumption preference shock $\varepsilon_{d, t}$ and labour supply shock $\varepsilon_{l, t}$.

\subsubsection{Consumption choice}

The first order conditions to the representative consumer's maximization problem imply the following conventional stochastic Euler equation: 


$$
\beta R_{t} E_{t}\left\{\frac{\varepsilon_{d, t+1}}{\varepsilon_{d, t}}\left(\frac{C_{t+1}-h C_{t}}{C_{t}-h C_{t-1}}\right)^{-\sigma} \frac{P_{C, t}}{P_{C, t+1}}\right\}=1
$$

The consumption bundle $C_{t}$ consists of final tradable goods $C_{T, t}$ and nontradable goods $C_{N, t}$, aggregated according to:

$$
C_{t}=\frac{C_{T, t}^{\gamma_{c}} C_{N, t}^{1-\gamma_{c}}}{\gamma_{c}^{\gamma_{c}}\left(1-\gamma_{c}\right)^{1-\gamma_{c}}}
$$

where $\gamma_{c}$ denotes the share of tradable goods in the total consumption of home households.

Following Burstein et al. (2003), ${ }^{7}$ we assume that consuming a final tradable good requires $\omega$ units of nontradable distribution services $Y_{D}$ :

$$
C_{T, t}=\min \left\{C_{R, t} ; \omega^{-1} Y_{D}\right\}
$$

The index of raw tradable goods is defined by:

$$
C_{R, t}=\frac{C_{H, t}^{\alpha} C_{F, t}^{1-\alpha}}{\alpha^{\alpha}(1-\alpha)^{1-\alpha}}
$$

where $C_{H, t}$ is the bundle of home-made raw tradable goods consumed at home, $C_{F, t}$ is the bundle of foreign-made raw tradable goods consumed at home and $\alpha$ denotes the share of home goods in the home basket of tradable goods.

The indices of nontradable and both types of tradable goods are in turn given by the following aggregators of individual varieties:

$$
\begin{gathered}
C_{N, t}=\left[\left(\frac{1}{n}\right)^{\frac{1}{\phi}} \int_{0}^{n} C_{t}\left(z_{N}\right)^{\frac{\phi-1}{\phi}} d z_{N}\right]^{\frac{\phi}{\phi-1}} \\
C_{H, t}=\left[\left(\frac{1}{n}\right)^{\frac{1}{\phi}} \int_{0}^{n} C_{t}\left(z_{H}\right)^{\frac{\phi-1}{\phi}} d z_{H}\right]^{\frac{\phi}{\phi-1}} \\
C_{F, t}=\left[\left(\frac{1}{1-n}\right)^{\frac{1}{\phi}} \int_{n}^{1} C_{t}\left(z_{F}\right)^{\frac{\phi-1}{\phi}} d z_{F}\right]^{\frac{\phi}{\phi-1}}
\end{gathered}
$$

where $\phi$ is the elasticity of substitution across varieties of a given type.

The sequence of intratemporal optimization problems implies the following demand functions for each variety of goods:

$$
\begin{gathered}
C_{t}\left(z_{N}\right)=\frac{1}{n}\left(1-\gamma_{c}\right)\left(\frac{p_{t}\left(z_{N}\right)}{P_{N, t}}\right)^{-\phi}\left(\frac{P_{N, t}}{P_{C, t}}\right)^{-1} C_{t} \\
C_{t}\left(z_{H}\right)=\frac{1}{n} \gamma_{c} \alpha\left(\frac{p_{t}\left(z_{H}\right)}{P_{H, t}}\right)^{-\phi}\left(\frac{P_{H, t}}{P_{R, t}}\right)^{-1}\left(\frac{P_{T, t}}{P_{C, t}}\right)^{-1} C_{t} \\
C_{t}\left(z_{F}\right)=\frac{1}{1-n} \gamma_{c}(1-\alpha)\left(\frac{p_{t}\left(z_{F}\right)}{P_{F, t}}\right)^{-\phi}\left(\frac{P_{F, t}}{P_{R, t}}\right)^{-1}\left(\frac{P_{T, t}}{P_{C, t}}\right)^{-1} C_{t}
\end{gathered}
$$

where $p_{t}\left(z_{j}\right)$ is the price of variety $z_{j}$, while the composite price indexes are defined as follows:

$$
P_{N, t}=\left[\frac{1}{n} \int_{0}^{n} P_{t}\left(z_{N}\right)^{1-\phi} d z_{N}\right]^{\frac{1}{1-\phi}}
$$

\footnotetext{
${ }^{7}$ See also Corsetti and Dedola (2005).
} 


$$
\begin{gathered}
P_{H, t}=\left[\frac{1}{n} \int_{0}^{n} P_{t}\left(z_{H}\right)^{1-\phi} d z_{H}\right]^{\frac{1}{1-\phi}} \\
P_{F, t}=\left[\frac{1}{1-n} \int_{0}^{n} P_{t}\left(z_{F}\right)^{1-\phi} d z_{F}\right]^{\frac{1}{1-\phi}} \\
P_{R, t}=P_{H, t}^{\alpha} P_{F, t}^{1-\alpha} \\
P_{T, t}=P_{R, t}+\omega P_{N, t} \\
P_{C, t}=P_{T, t}^{\gamma} P_{N, t}^{1-\gamma}
\end{gathered}
$$

The optimization problem, demand functions and price indexes for the foreign economy are defined in an analogous way.

\subsubsection{Investment decisions}

Households spend part of their income on a homogenous investment good, which is transformed into the capital stock $K_{t+1}$ according to the formula:

$$
K_{t+1}=(1-\tau) K_{t}+\varepsilon_{t}^{I}\left(1-S\left(\frac{I_{t}}{I_{t-1}}\right)\right) I_{t}
$$

where $\tau$ is the depreciation rate. As in Christiano et al. (2005), capital accumulation is subject to investment-specific technological progress $\varepsilon_{t}^{I}$ and adjustment cost represented by function $S(\bullet)$, which satisfies the following properties: $S(1)=S^{\prime}(1)=0, S^{\prime \prime}(\bullet) \equiv S^{\prime \prime}>0$.

The first order conditions to the consumer's maximization problem imply:

$$
\begin{gathered}
\frac{P_{I, t}}{P_{C, t}}+\varepsilon_{t}^{I}\left(1-S\left(\frac{I_{t}}{I_{t-1}}\right)-\frac{I_{t}}{I_{t-1}} S^{\prime}\left(\frac{I_{t}}{I_{t-1}}\right)\right) Q_{T, t}+E_{t}\left\{\frac{P_{C, t+1}}{P_{C, t} R_{t}} \varepsilon_{t+1}^{I}\left(\frac{I_{t+1}}{I_{t}}\right)^{2} S^{\prime}\left(\frac{I_{t+1}}{I_{t}}\right)\right\}=0 \\
Q_{T, t}=E_{t}\left\{\frac{R_{t+1}^{k}}{P_{C, t+1}} \frac{P_{C, t+1}}{P_{C, t} R_{t}}\right\}+(1-\tau) E_{t}\left\{\frac{P_{C, t+1}}{P_{C, t} R_{t}} Q_{T, t+1}\right\}
\end{gathered}
$$

Equation (20) can be interpreted as investment demand, while equation (21) determines the price of installed capital, defined as:

$$
Q_{T, t} \equiv \frac{\lambda_{K, t}}{\lambda_{C, t} P_{C, t}}
$$

where $\lambda_{C, t}$ is the marginal utility of consumption (which is the Lagrange multiplier on households' budget constraint) and $\lambda_{K, t}$ is the Lagrange multiplier on the capital law of motion.

The homogeneous investment good is produced in a similar fashion as the final consumption good, except that there are no distribution costs associated with supplying its tradable component, ${ }^{8}$ which implies the following definitions:

$$
\begin{gathered}
I_{t}=\frac{I_{R, t}^{\gamma_{I}} I_{N, t}^{1-\gamma_{I}}}{\gamma_{I}^{\gamma_{I}}\left(1-\gamma_{I}\right)^{1-\gamma_{I}}} \\
I_{R, t}=\frac{I_{H, t}^{\alpha} I_{F, t}^{1-\alpha}}{\alpha^{\alpha}(1-\alpha)^{1-\alpha}} \\
P_{I, t}=P_{R, t}^{\gamma_{i}} P_{N, t}^{1-\gamma_{i}}
\end{gathered}
$$

\footnotetext{
${ }^{8}$ This is motivated by the evidence provided by Burstein et al. (2003).
} 
Hence, while we allow for differences in the tradable-nontradable composition between the final consumption basket and the investment basket (i.e. $\gamma_{c}$ need not be equal to $\gamma_{i}$ ), we assume that the structure of the purely tradable component is identical for both types of goods. This simplifies calibration discussed in section 4 .

\subsubsection{Wage setting}

Each household in the home country supplies monopolistically one distinctive type of labour $L(j)$, which is aggregated with labour services of other households into a homogenous labour input according to the formula:

$$
L_{t}=\left[\left(\frac{1}{n}\right)^{\frac{1}{\phi}} \int_{0}^{n} L_{t}(j)^{\frac{\phi-1}{\phi}}\right]^{\frac{\phi}{\phi-1}}
$$

We follow Erceg et al. (2000) and assume that only a fraction $1-\theta_{W}$ of households can renegotiate their wage contracts in each period, while wages of the remaining households are partially indexed to the past CPI inflation:

$$
W_{t}(j)=W_{t-1}(j)\left(\frac{P_{C, t-1}}{P_{C, t-2}}\right)^{\delta_{W}}
$$

Households that are allowed to reset their wages take into account that they may not be allowed to do so for some time, so they solve the following optimization problem:

$$
E_{t} \sum_{k=0}^{\infty} \theta_{W}^{k} \beta^{k}\left[-\frac{\varepsilon_{l, t+k}}{1+\varphi} L_{t+k}(j)^{1+\varphi}+\lambda_{t+k}^{C} \beta^{-k} W_{t}(j)\left(\frac{P_{C, t+k-1}}{P_{C, t-1}}\right)^{\delta_{W}} L_{t+k}(j)\right]
$$

subject to the sequence of labour demand constraints:

$$
L_{t+k}(j)=\frac{1}{n}\left[\frac{W_{t}(j)}{W_{t+k}}\left(\frac{P_{C, t+k-1}}{P_{C, t-1}}\right)^{\delta_{W}}\right]^{-\phi} L_{t+k}
$$

where the aggregate wage index is given by:

$$
W_{t}=\left[\frac{1}{n} \int_{0}^{n} W_{t}(j)^{1-\phi} d j\right]^{\frac{1}{1-\phi}}
$$

The first-order condition associated with the optimization problem (28) can be written as:

$$
E_{t} \sum_{k=0}^{\infty} \theta_{W}^{k} \beta^{k}\left[\frac{W_{t}(j)}{P_{t+k}^{C}}\left(\frac{P_{C, t+k-1}}{P_{C, t-1}}\right)^{\delta_{W}}-\frac{\phi}{\phi-1} M R S_{t+k}(j)\right] \varepsilon_{d, t+k}\left(C_{t+k}(j)-h C_{t+k-1}\right)^{-\sigma} L_{t+k}(j)=0
$$

where $M R S_{t}$ is the marginal rate of substitution between consumption and labour defined as:

$$
M R S_{t}(j)=\frac{\varepsilon_{l, t} L_{t}(j)^{\varphi}}{\varepsilon_{d, t}\left(C_{t}(j)-h C_{t-1}\right)^{-\sigma}}
$$

Since all households that can renegotiate their wage contracts face an identical optimization problem, they set the same optimal wage $\tilde{W}_{t}$, which implies the following formula for the evolution of the aggregate wage index:

$$
W_{t}=\left[\theta_{W}\left(W_{t-1}\left(\frac{P_{C, t-1}}{P_{C, t-2}}\right)^{\delta_{W}}\right)^{1-\phi}+\left(1-\theta_{W}\right) \tilde{W}_{t}^{1-\phi}\right]^{\frac{1}{1-\phi}}
$$

The wage setting problem faced by foreign households is similar and leads to an analogous first-order condition and aggregate wage law of motion to those given by equations (31) and (33). Yet, the structural parameters governing the wage setting $\left(\theta_{W}\right.$ and $\left.\delta_{W}\right)$ are allowed to vary across countries. 


\section{$2.2 \quad$ Firms}

\subsubsection{Production technology}

There exist a continuum of identically monopolistic competitive firms in each of the tradable and nontradable sectors of the domestic economy. The production technology is homogenous with respect to labour and capital inputs:

$$
\begin{aligned}
& Y_{t}\left(z_{N}\right)=\varepsilon_{a^{N}, t} L_{t}\left(z_{N}\right)^{1-\eta} K_{t}\left(z_{N}\right)^{\eta} \\
& Y_{t}\left(z_{H}\right)=\varepsilon_{a^{H}, t} L_{t}\left(z_{H}\right)^{1-\eta} K_{t}\left(z_{H}\right)^{\eta}
\end{aligned}
$$

where $\eta$ is output elasticity with respect to capital (common across sectors but not necessarily across countries), while $\varepsilon_{a^{N}, t}$ and $\varepsilon_{a^{H}, t}$ are sector specific productivity parameters. The output index in each sector is given by the Dixit-Stiglitz aggregators:

$$
\begin{aligned}
& Y_{N, t}=\left[\left(\frac{1}{n}\right)^{\frac{1}{\phi}} \int_{0}^{n} Y_{t}\left(z_{N}\right)^{\frac{\phi-1}{\phi}} d z_{N}\right]^{\frac{\phi}{\phi-1}} \\
& Y_{H, t}=\left[\left(\frac{1}{n}\right)^{\frac{1}{\phi}} \int_{0}^{n} Y_{t}\left(z_{H}\right)^{\frac{\phi-1}{\phi}} d z_{H}\right]^{\frac{\phi}{\phi-1}}
\end{aligned}
$$

Since all firms operate technologies with the same relative intensity of productive factors and face the same prices for labour and capital inputs, cost minimization implies the following capital-labour ratio, identical across all domestic firms:

$$
\frac{W_{t} L_{t}}{R_{t}^{k} K_{t}}=\frac{1-\eta}{\eta}
$$

\subsubsection{Price setting}

Firms set their prices according to a modified version of the Calvo (1983) staggering mechanism. Only a fraction $1-\theta_{N}$ of firms producing nontradable goods set their prices in a forward-looking manner, while the prices of firms that do not receive a price signal are indexed to the past inflation according to the following rule:

$$
P_{t}\left(z_{N}\right)=P_{t-1}\left(z_{N}\right)\left(\frac{P_{N, t-1}}{P_{N, t-2}}\right)^{\delta_{N}}
$$

where $\delta_{N}$ is the degree of indexation in nontradable prices.

Firms that are allowed to reoptimize their prices realize that they may not be allowed to do so for some time, hence their price-setting problem is to maximize the expected present discounted value of future profits:

$$
E_{t} \sum_{k=0}^{\infty} \theta_{N}^{k} \beta^{k} \lambda_{t+k} Y_{t+k}\left(z_{N}\right)\left[P_{t}\left(z_{N}\right)\left(\frac{P_{N, t+k-1}}{P_{N, t-1}}\right)^{\delta_{N}}-P_{N, t+k} M C_{t+k}\right]
$$

subject to the sequence of demand constraints:

$$
Y_{t+k}\left(z_{N}\right)=\frac{1}{n}\left[\frac{P_{t}\left(z_{N}\right)}{P_{N, t+k}}\left(\frac{P_{N, t+k-1}}{P_{N, t-1}}\right)^{\delta_{N}}\right]^{-\phi} Y_{N, t+k}
$$

where $\lambda_{t}$ is the marginal utility of households' nominal income (exogenous to firms) and $M C_{t}$ is the real marginal cost (identical across firms from a given sector since factor markets are homogenous) defined as:

$$
M C_{t}=\frac{1}{P_{N, t} \varepsilon_{a^{N}, t}}\left(\frac{W_{t}}{1-\eta}\right)^{1-\eta}\left(\frac{R_{t}^{k}}{\eta}\right)^{\eta}
$$


The first-order condition associated with the profit-maximization problem faced by reoptimizing firms can be written as:

$$
E_{t} \sum_{k=0}^{\infty} \theta_{N}^{k} \beta^{k} \lambda_{t+k} Y_{t+k}\left(z_{N}\right)\left[P_{t}\left(z_{N}\right)\left(\frac{P_{N, t+k-1}}{P_{N, t-1}}\right)^{\delta_{N}}-\frac{\phi}{\phi-1} P_{N, t+k} M C_{t+k}\right]=0
$$

There are no firm-specific shocks in the model, so all firms that are allowed to reset their price in a forward-looking manner select the same optimal price $\tilde{P}_{N, t}$, which implies the following expression for the evolution of the home nontradable goods price index:

$$
P_{N, t}=\left[\theta_{N}\left(P_{N, t-1}\left(\frac{P_{N, t-1}}{P_{N, t-2}}\right)^{\delta_{N}}\right)^{1-\phi}+\left(1-\theta_{N}\right) \tilde{P}_{N, t}^{1-\phi}\right]^{\frac{1}{1-\phi}}
$$

The price-setting problem solved by home firms producing tradable goods and firms in the foreign country is similar and leads to first-order conditions and price indices analogous to equation (43) and (44), respectively. Yet, structural parameters governing the pricing behaviour $(\theta$ and $\delta)$, as well as stochastic properties of productivity shocks, are allowed to vary across countries and sectors.

We assume that prices are set in the producer currency and that the international law of one price holds for raw tradable goods at the dock. Therefore, the price of home goods sold abroad and that of foreign goods sold domestically are given by:

$$
P_{H, t}^{*}=E R_{t}^{-1} P_{H, t} \quad P_{F, t}=E R_{t} P_{F, t}^{*}
$$

where $E R_{t}$ is the nominal exchange rate expressed as units of domestic currency per one unit of foreign currency.

\subsection{International risk sharing}

Assuming complete markets implies the following perfect risk-sharing condition (see Chari et al., 2002):

$$
Q_{t}=\kappa \frac{\varepsilon_{d, t}^{*}}{\varepsilon_{d, t}} \frac{\left(C_{t}^{*}-h^{*} C_{t-1}^{*}\right)^{-\sigma^{*}}}{\left(C_{t}-h C_{t-1}\right)^{-\sigma}}
$$

where $\kappa$ is a constant depending on initial conditions and $Q_{t}$ is the real exchange rate defined as:

$$
Q_{t}=\frac{E R_{t} P_{C, t}^{*}}{P_{C, t}}
$$

The real exchange rate is allowed to deviate from the purchasing power parity ( $\mathrm{PPP}$ ) due to changes in relative prices of tradable vs. nontradable goods in both countries (so-called internal exchange rates), changes in relative distribution costs and changes in terms-of-trade, as long as there is some home bias in preferences $\left(\alpha \neq \alpha^{*}\right)$. This can be demonstrated using the price indices derived above and the law of one price conditions for raw tradable goods:

$$
Q_{t}=S_{t}^{\alpha-\alpha^{*}} \frac{1+\omega^{*} D_{t}^{*}}{1+\omega D_{t}} \frac{X_{t}^{* 1-\gamma^{*}}}{X_{t}^{1-\gamma}}
$$

where terms-of-trade $S_{t}$ are defined as home import prices relative to home export prices:

$$
S_{t}=\frac{E R_{t} P_{F, t}^{*}}{P_{H, t}}
$$

the internal exchange rates $X_{t}$ and $X_{t}^{*}$ are defined as:

$$
X_{t}=\frac{P_{N, t}}{P_{T, t}} \quad X_{t}^{*}=\frac{P_{N, t}^{*}}{P_{T, t}^{*}}
$$

and relative distribution costs are given by: 


$$
D_{t}=\frac{P_{N, t}}{P_{R, t}} \quad D_{t}^{*}=\frac{P_{N, t}^{*}}{P_{R, t}^{*}}
$$

\subsection{Monetary and fiscal authorities}

We assume that monetary authorities in both countries respond to the economic conditions through the following interest-rate feedback rules:

$$
R_{t}=R_{t-1}^{\rho}\left[\left(\frac{Y_{t}}{\bar{Y}}\right)^{\phi_{y}}\left(\frac{P_{C, t}}{(1+\bar{\pi}) P_{C, t-1}}\right)^{\phi_{\pi}}\right]^{1-\rho} \varepsilon_{m, t}
$$

where $\bar{Y}$ is steady state output, $\bar{\pi}$ is steady state CPI inflation and $\varepsilon_{m, t}$ is a monetary policy shock.

Fiscal authorities are modelled in a very simplistic fashion: government expenditures and transfers to the households are fully financed by lump sum taxes, so that the state budget is balanced each period. The government spending is fully directed at nontradable goods and is modelled as a stochastic process $\varepsilon_{g, t}$. Given our representative agent assumption, Ricardian equivalence holds in the model.

\subsection{Market clearing conditions}

The model is closed by imposing the following market clearing conditions. Output of each firm producing non-tradable goods is either consumed domestically, spent on investment or used for distribution services or purchased by the government. Similarly, all tradable goods are consumed or invested domestically or abroad. Using these conditions together with demand functions (10), (11), (12), the output indexes given by (36), (37) and their analogs for investment goods, one can write the aggregate output in the two sectors at home as:

$$
\begin{aligned}
Y_{N, t}=\left(1-\gamma_{c}\right)\left(\frac{P_{N, t}}{P_{t}}\right)^{-1} C_{t}+\omega \gamma_{c}\left(\frac{P_{T, t}}{P_{C, t}}\right)^{-1} C_{t}+\left(1-\gamma_{i}\right)\left(\frac{P_{N, t}}{P_{I, t}}\right)^{-1} I_{t}+G_{t} \\
Y_{H, t}=\alpha \gamma_{c}\left(\frac{P_{H, t}}{P_{R, t}}\right)^{-1}\left(\frac{P_{T, t}}{P_{C, t}}\right)^{-1} C_{t}+\frac{1-n}{n} \alpha^{*} \gamma_{c}^{*}\left(\frac{P_{H, t}^{*}}{P_{R, t}^{*}}\right)^{-1}\left(\frac{P_{R, t}^{*}}{P_{C, t}^{*}}\right)^{-1} C_{t}^{*} \\
+\alpha \gamma_{i}\left(\frac{P_{H, t}}{P_{R, t}}\right)^{-1}\left(\frac{P_{T, t}}{P_{I, t}}\right)^{-1} I_{t}+\frac{1-n}{n} \alpha^{*} \gamma_{i}^{*}\left(\frac{P_{H, t}^{*}}{P_{R, t}^{*}}\right)^{-1}\left(\frac{P_{R, t}^{*}}{P_{I, t}^{*}}\right)^{-1} I_{t}^{*}
\end{aligned}
$$

where in (53) we make use of the following optimality condition linking distribution services with tradable consumption goods:

$$
Y_{D, t}=\omega C_{T, t}
$$

Market clearing conditions for the foreign economy are derived in a similar fashion.

Finally, equilibrium in factor markets requires:

$$
\begin{aligned}
L_{t} & =\int_{0}^{n} L_{t}\left(z_{N}\right)+\int_{0}^{n} L_{t}\left(z_{H}\right) \\
K_{t} & =\int_{0}^{n} K_{t}\left(z_{N}\right)+\int_{0}^{n} K_{t}\left(z_{H}\right)
\end{aligned}
$$




\subsection{Log-linearized model}

The model does not have a closed-form solution. Therefore, we log-linearize it around the non-stochastic steady state. The full list of log-linearized model equations is available in the technical appendix.

Our two-country model is driven by fourteen stochastic shocks, seven for each country. Preference, labour supply, government spending, investment efficiency and productivity shocks in the two sectors are assumed to follow first-order autoregressive processes, while monetary policy shocks are assumed to be white noise. Monetary policy shocks and the IID innovations to the remaining types of shocks are allowed to be correlated across countries.

\section{Estimation}

\subsection{Data considerations}

The model is fitted to the data using fourteen macroeconomic variables, seven for each country. The estimation sample covers the period 1996q2-2007q2, which makes 45 quarterly observations for each variable. The indicators considered are: (real) GDP private consumption, investment, CPI, the internal exchange rate, ${ }^{9}$ the real wage rate (all expressed as log changes) and the nominal short-term (3 month) interest rate. All variables are seasonally adjusted (except for interest rates) and demeaned prior to estimation. Additionally, the CPI inflation and interest rate series for Poland were detrended with the inflation target data, which was constructed using monetary policy guidelines published by the NBP.

All data for the euro area come from Eurostat. The time series for Poland were taken from the ECMOD database, maintained at the NBP. The only exception is tradable and non-tradable goods inflation, the source of which is Eurostat.

\subsection{Bayesian estimation}

We fit our model using a Bayesian approach, which consists in placing a priori distribution $p(\Theta)$ on the structural parameters $\Theta$, the estimates of which are then updated using the data $Z$ according to the Bayes rule:

$$
p(\Theta \mid Z)=\frac{p(Z \mid \Theta) p(\Theta)}{p(Z)} \propto L(\Theta \mid Z) p(\Theta)
$$

where $L(\Theta \mid Z)=P(Z \mid \Theta)$ is the likelihood function, $p(\Theta \mid Z)$ is the posterior distribution of parameters and $p(Z)$ is the marginal likelihood (marginal data density) defined as:

$$
p(Z)=\int p(Z \mid \Theta) p(\Theta) d \Theta
$$

Our model forms a linear system with rational expectations, the solution to which is of the form:

$$
\begin{aligned}
H_{t} & =A_{1}(\Theta) H_{t-1}+A_{2}(\Theta) \varepsilon_{t} \\
\varepsilon_{t} & =A_{3}(\Theta) \varepsilon_{t-1}+A_{4}(\Theta) \epsilon_{t}
\end{aligned}
$$

where $H_{t}$ is a vector of endogenous variables, $\varepsilon_{t}$ is a vector of stochastic disturbances, $\epsilon_{t}$ groups innovations to stochastic disturbances and $A_{i}, i=1,2,3,4$, are matrices depending on the parameters of the model. The measurement equation, linking observable variables used in the estimation $\left(Z_{t}\right)$ with endogenous variables of the model can be written as:

$$
Z_{t}=B H_{t}
$$

where $B$ is a deterministic matrix.

\footnotetext{
${ }^{9}$ Prices of non-tradable goods relative to prices of tradable goods are based on the HICP basket, with services and energy goods treated as nontradable, while the remaining components assumed to be tradable.
} 
Equation (62) together with the system of state equations (60), (61) form the state-space representation of the model, the likelihood of which can be evaluated using the Kalman filter. Obtaining the analytical expression for the likelihood function is generally not possible. However, the posterior distribution of the model parameters can be constructed numerically by applying the Markov Chain Monte Carlo (MCMC) methods. We compute the posterior moments of the parameters using a sufficiently large number of draws, having made sure that the MCMC algorithm converged.

\subsection{Calibrated parameters and prior distributions}

Since our sample is rather short, we calibrate rather than estimate those structural parameters of our model, for which we have relatively good information or which are known to be weakly identified in this type of models. This strategy can be seen as equivalent to imposing very strict priors on a subset of parameters. Such a mixed approach is quite common in the literature and may lead to more efficient estimates of the non-calibrated parameters (see Canova, 2007).

We set the parameter governing the relative size of Poland and the euro area $n$ to 0.029 , which is the value implied by nominal GDP levels, averaged over the period 1997-2006. The share of final tradable consumption goods in Poland $\gamma_{c}$ and in the euro area $\gamma_{c}^{*}$ is set to 0.61 and 0.52 , respectively. This corresponds to the average shares of services and energy goods in the HICP baskets for both countries over 1997-2006. The distribution cost parameters $\omega$ and $\omega^{*}$ are calibrated at 1, which follows the discussion in Burstein et al. (2003) and implies the share of distribution services in the total price of final tradable consumption goods of $50 \%$. The share of tradable investment goods in Poland $\gamma_{i}$ and in the euro area $\gamma_{i}^{*}$ are set to 0.45 and 0.48 , respectively, which corresponds to the respective average shares of non-construction works in total investment expenditures over the period 1997-2006, taken from Eurostat. The share of Polish goods in the raw tradable baskets are calculated using the data on bilateral trade flows between Poland and the euro area, assuming the import content of exports at $32 \%$, which is roughly the value implied by the input-output tables. This gives $\alpha=0.6$ for Poland and $\alpha^{*}=0.015$ for the euro area.

We set the discount factor in each country $\left(\beta\right.$ and $\left.\beta^{*}\right)$ to its conventional value of 0.99 , implying an annual steady-state real interest rate of $4 \%$. The quarterly depreciation rates $\tau$ and $\tau^{*}$ are calibrated at 0.025 , which is close to the values assumed in the standard business cycle literature. The output elasticity of capital input in Poland $\eta$ and in the euro area $\eta^{*}$ is set to 0.33 and 0.3 , respectively. This roughly corresponds to one minus labour shares in both economies, corrected for implicit labour income of self-employed persons. Given well-known problems with the identification of the elasticity of substitution across different varieties of labour $\left(\phi\right.$ and $\phi^{*}$ ), we follow Smets and Wouters (2003) and set this parameter equal to 3, which implies a wage mark-up of $50 \%$.

Steady state shares of consumption, government spending and investment in total output correspond to domestic demand ratios of private consumption, public consumption and gross capital formation, respectively, taken from Eurostat and averaged over the period 1997-2006. Steady state output shares of tradable and nontradable production are straightforward to derive using the calibrations described so far.

We choose the type and parametrization of the prior distributions for the euro area relying largely on earlier contributions to Bayesian estimation of DSGE models, including Smets and Wouters (2003), Lubik and Schorfheide (2006), Jondeau and Sahuc (2005) and Pytlarczyk (2005). ${ }^{10}$ For lack of relevant studies on Poland, prior distributions for most of parameters describing the Polish economy are chosen to be the same as their euro area counterparts. An important exception are standard deviations of the stochastic disturbances, which are assumed to be three times larger than in the euro area. This is roughly the magnitude implied by the cross-country differences in volatility of the observable variables used in the estimation. Finally, given evidence on relatively weak correlation between structural shocks within the euro area (see e.g. Jondeau and Sahuc, 2005), we find it reasonable to set the mean of the prior distribution for the relevant shock correlations between Poland and the euro area to zero rather than to a positive value, with a relatively large standard deviation.

\footnotetext{
${ }^{10}$ We make a slight departure from the earlier studies in the case of parameters describing the degree of indexation in price and wage setting, chosing their prior means equal to 0.5 rather than around 0.75 and making their distributions less informative. This was motivated by the results of preliminary estimations using the more conventional parametrization: they yielded a posteriori estimates with variance not much different (or even lower) to that of the prior distribution, signalling a potential problem with the priors. Similar considerations motivate assuming slightly higher prior mean of output weight in the monetary policy reaction function (2 vs. conventional 1.5) and intertemporal elasticity of substitution (1.5 vs. more standard 1).
} 


\subsection{Estimation results}

The complete set of estimation results, including information on prior distributions, is reported in Table 1 (structural parameters) and Table 2 (shocks). ${ }^{11}$ The posterior maximization is performed using the csminwel, which is a numerical routine developed by Sims (2002). The posterior parameter space is explored using the Metropolis-Hastings algorithm. ${ }^{12}$ The reported estimates are obtained from the last 200,000 draws out of the total of 800,000 runs. $^{13}$

[Table 1 and Table 2 about here]

Overall, all structural parameters except for those related to the degree of price indexation are estimated significantly different from zero. This is also true for standard deviations and autoregressive parameters of stochastic disturbances, but not necessarily so for correlations of some types of shocks across Poland and the euro area. Judging by the comparisons between prior and posterior distributions (see Figure 1 and 2), the data seems to be quite informative for most of parameters. The only parameters for which the prior distribution is essentially not updated are elasticity of labour supply in both countries and inertia of productivity shock in the euro area nontradable sector. It has to be noted, however, that the posterior distributions cannot be regarded as very tight for all parameters. In particular, the variance of posterior estimates of some parameters is very close to that of the relevant prior distributions. This is particularly true for the elasticity of intertemporal substitution, inflation weight in the monetary policy rule and the parameters governing the law of motion of labour supply shocks. All in all, it is fair to say that there is a sizable amount of uncertainty surrounding some of our estimates.

[Figure 1 and Figure 2 about here]

In what follows, we first focus on point estimates of the structural parameters (using posterior means) and a visual inspection of shapes of their marginal posterior distributions. A more formal examination of heterogeneity between our two model economies is postponed to section 5 .

\subsubsection{Structural parameters}

Starting from parameters characterizing the utility function, we do not find sizable differences between Poland and the euro area. The external habit in consumption seems to be somewhat larger in Poland, while the cross-country discrepancies between implied elasticities of intertemporal substitution and of labour supply are negligible. Similarly, there seems to be a high degree of homogeneity between the two countries in terms of curvature of the capital adjustment cost function. All four pairs of parameters fall well within the range implied by earlier estimates obtained for the euro area or other developed economies.

Turning to the set of parameters governing the degree of price and wage stickiness, the heterogeneity across our two model economies is more pronounced. According to our estimates, wage indexation to past inflation in Poland is more than twice as large as that in the euro area. This suggests that second round effects should be of relatively bigger concern to authorities pursuing price stabilization policies in Poland. It has to be noted, however, that the degree of wage indexation in both countries is rather moderate if compared to previous studies. Similarly, our results point at relatively weak indexation mechanisms in the price setting behaviour in both countries, with only slightly higher weight on past inflation in Poland's tradable sector relative to that prevailing in the euro area.

As regards Calvo probability estimates, our results are quite mixed. We find that wages are less sticky in Poland, tradable goods prices are somewhat more flexible in the euro area, while a similar degree of Calvo stickiness across the two economies can be observed for prices of nontradables. If compared with earlier studies relying on estimated DSGE models, our results point at much weaker Calvo stickiness in the euro area price setting behaviour. For instance, Smets and Wouters (2003) and Pytlarczyk (2005) estimate the average duration of the price contracts at two and a half or four years, respectively. Our results suggest a

\footnotetext{
${ }^{11}$ The software used is dynare, which is a set of routines for solving and estimating models with forward-looking variables, developed at CEPREMAP. For details on the current version of the software, see http://www.cepremap.cnrs.fr/dynare.

${ }^{12}$ See Chib and Greenberg (1995) for an excellent exposition to this algorithm.

${ }^{13}$ Convergence of the Markov chains generated by the Metropolis-Hastings algorithm was assessed qualitatively using diagnostic charts developed by Brooks and Gelman (1998).
} 
frequency of price changes of around three and a half quarters (weighted average for tradable and nontradable goods), which is very close to estimates obtained from microeconomic surveys for the euro area (see Altissimo et al., 2006).

Our estimation delivers similar long run monetary feedback rules in both economies, with that for Poland exhibiting a slightly higher weight of output relative to inflation. An important difference concerns the degree of interest rate smoothing, which seems to be more important in the euro area. For both economies, the estimated monetary policy reaction functions satisfy the so-called Taylor principle, i.e. the long run response to inflation exceeds one.

\subsubsection{Shock parameters}

The point posterior estimates of autoregressive coefficients of shock processes suggest that their inertia in Poland is larger than in the euro area. The only exception is the labour supply shock, which seems to be somewhat more persistent in the latter region. It has to be noted, however, that the differences across countries do not seem to be very large if one takes into account the precision of posterior distributions.

The posterior estimates of shock volatilities confirm our prior assumption about their heterogeneity across the two countries. Standard deviations of stochastic disturbances are on average more than three and a half times higher in Poland than in the euro area. The largest discrepancy between shock volatilities across the two countries concerns the government spending shock, which is five times more volatile in Poland than in the euro area. The least heterogeneous disturbance is the productivity shock in the nontradable sector, but still its standard deviation in Poland turns out more than two and a half times larger than in the euro area.

We do not find any evidence for significant cross-country correlation of productivity shocks in tradables, government spending shocks and monetary policy shocks. Preference, labour supply and investment efficiency shocks turn out to be positively correlated, while productivity shocks in the nontradable sector are negatively correlated. Overall, our results suggest that structural shocks are rather weakly correlated across Poland and the euro area. It has to be noted, however, that the shocks are probably far from being perfectly correlated even between highly integrated EMU countries. ${ }^{14}$ For instance, using a more parsimonious DSGE setup with three stochastic disturbances, Jondeau and Sahuc (2005) find very weak correlation across shocks hitting the largest euro area countries (Germany, Italy and France). ${ }^{15}$ Their results are broadly confirmed by a less parsimonious study by Pytlarczyk (2005), focusing on the links between Germany and the rest of the euro area.

\subsection{Alternative priors}

While the main merit of the Bayesian approach is the possibility to incorporate a priori knowledge into the estimation procedure, the choice of the prior might significantly affect the posterior results if the sample size is short or if some of the model parameters are not identified. Therefore, it is important to check to what extent our results are driven by the imposed prior assumptions.

Ideally, one could reestimate the model using uninformative prior distributions, e.g. by following the restricted maximum likelihood approach. ${ }^{16}$ Unfortunately, the results are rarely satisfactory, i.e. the maximization of the likelihood is imprecise due to the presence of large flat regions and the parameter estimates tend to settle on the boundaries of the prior range. In our case, these problems turn out to be severe enough to make the estimation relying on uninformative priors for all parameters virtually infeasible. Hence, we perform our sensitivity analysis in several steps, each time imposing uniform prior distributions for a different subset of the estimated parameters.

If we replace our baseline prior distributions for the utility function parameters and the capital adjustment cost curvature, the precision of the estimates drops dramatically. While in this case comparing the estimated posterior modes to those from the baseline is of little use, we note that the inverse of the elasticity of intertemporal substitution for both countries tends to approach the upper bound (set at 3) and the habit persistence coefficient in the euro area drops by half.

\footnotetext{
${ }^{14}$ One can expect that the observed and estimated correlations can be to some extent weakened by idiosyncratic measurement errors in the data.

${ }^{15}$ The highest correlation obtained by Jondeau and Sahuc (2005) in their baseline (unrestricted) model concerns preference shocks between Germany and France, but is estimated at only 0.313 .

${ }^{16}$ See e.g. Onatski and Williams (2004) who reestimate the Smets and Wouters (2003) model using uniform prior distributions.
} 
Assigning uniform distributions to the priors for parameters describing price and wage formation has the largest impact on the indexation coefficients. The degree of price indexation in both tradable and nontradable sectors is on the zero bound for both countries, while the wage indexation parameters fall by more than half. Calvo probabilities in nontradable sectors and in wage setting are virtually unaffected, while the estimated degree of price stickiness in each country's tradable sector turns out lower than in our baseline specification. The remaining parameters of the model do not change in a significant way.

Assuming uninformative priors for all monetary policy feedback parameters lowers the precision of the estimates. This is entirely due to problems with the relative weight of output and inflation in the euro area, which tend to be driven towards zero and the upper limit, respectively, whenever the other parameter is somewhat tied by an informative prior. If we reestablish informative priors for these parameters, the remaining ones (including the interest rate smoothing) are estimated very close to our baseline specification.

By allowing the prior distributions for serial correlation of the stochastic disturbances to be uniformly distributed over the unit interval we obtain half lower inertia for the productivity shock in the euro area tradable sector, while the government spending shock in this region turns out to be more persistent. In both countries, labour shocks are now estimated to be less inertial and more volatile. The remaining parameters are broadly unaffected.

Somewhat surprisingly, our results are relatively little affected if we assume uninformative priors for volatilities of the shocks. The only difference is somewhat higher variance of the tradable sector productivity, demand, labour supply and investment efficiency shocks in Poland.

Finally, we report that the estimation results turn out robust to the choice of priors for the cross correlation of the shocks. If anything, assuming uniform distributions for this group of parameters only slightly drives the estimates away from zero compared to our baseline specification.

All in all, we conclude that the prior distributions play an important role in estimation of some of our structural parameters, while they impinge far less on the estimates of parameters governing inertia, volatility and cross correlation of stochastic disturbances.

\section{Model evaluation}

\subsection{Dynamic properties}

\subsubsection{Variance decomposition}

We start the evaluation of dynamic properties of our model with discussing the results of the variance decomposition, based on means of parameter posterior distributions. The contribution of each of the structural shocks to the forecast error variance of the selected endogenous variables for Poland are presented in Tables 3 to $9 .^{17}$

[Table 3 to 9 about here]

It is apparent that most of the volatility of the main macrovariables in Poland is explained by idiosyncratic disturbances hitting the Polish economy, while the contribution of shocks originating in the euro area is rather limited. Generally, long run variations in the variables are driven almost entirely by supply shocks (i.e. productivity, investment efficiency and labour supply shocks), while in the short run there is also an important role for demand shocks.

Taking a closer look at short run determinants of volatility in the main variables, one can observe that the main source of output variations are government spending shocks and productivity shocks. Consumption and investment are mainly driven by preference and investment efficiency shocks, respectively. The dominant source of fluctuations in real wages are labour supply disturbances. Short run movements in the real exchange rate are significantly affected by virtually all shocks originating in Poland and the euro area productivity in the nontradable sector. Productivity shocks are the main factors behind variations in inflation. The same holds true for nominal interest rates, with the exception that in this case there is also an important role for monetary policy shocks.

\footnotetext{
${ }^{17}$ Since our model allows for cross-country correlation of shocks, we need to orthogonalize them before calculating variance decompositions and impulse response functions. This is done through a Cholesky decomposition of the shock covariance matrix, with the ordering that assigns all comovement of shocks to those originating in the euro area.
} 
Overall, the results of the variance decomposition in our model do not seem to deviate much from those obtained in other studies if one takes into account differences in the model structure. For instance, while interpreting the apparently high role of productivity disturbances in accounting for inflation volatility in our model, one should keep in mind that we do not include mark-up shocks as a separate source of fluctuations. One can therefore expect that some of the movements in productivity shocks identified in our model reflect also time-varying pricing power of the firms. ${ }^{18}$

\subsubsection{Impulse response analysis}

Figures 3 to 16 plot the impulse responses to orthogonalized innovations in stochastic disturbances for a set of selected variables. Similarly to the variance decomposition analysis, the parameters of the simulated model correspond to their posterior means.

\section{[Figure 3 to 16 about here]}

As one could expect, given the difference in size between our two model economies and the Cholesky ordering in orthogonalization, shocks originating in Poland have a negligible effect for the euro area, while the opposite holds true for the impact of euro area shocks on the Polish economy. Overall, the impulse responses in our model have a rather intuitive explanation in qualitative terms and are broadly in line with those obtained in other open economy DSGE models with sticky prices. Below we describe the main propagation mechanisms for each stochastic disturbance. It has to be kept in mind that, given the general equilibrium and forward looking nature of the model, the following description involves a considerable degree of simplification.

Productivity shocks originating in Poland lead to an expansion in this country's output, consumption, investment and real wages. Because of the presence of nominal rigidities, the response of labour input is negative (see e.g. Gali, 1999). Falling marginal costs cause a decline in inflation, to which the central bank reacts by lowering interest rates. The exchange rate depreciates in response to both tradable and nontradable shocks, which in the former case means that the home bias channel dominates the effect of changes in the internal exchange rate and relative distribution costs. Given the estimated differences in inertia, the persistence of the nontradable productivity shock is much higher than that of the productivity shock in the tradable sector.

Productivity shocks originating in the euro area have non-negligible effects for both economies. Except for output, the euro area tradable sector disturbances lead to qualitatively similar responses of the main variables in both economies. This is not the case for the euro area nontradable sector productivity disturbance, which leads to negative comovements in the main macrocategories. To large extent, this is due to negative crosscountry correlation of this type of shock. If we set the correlation to zero, only output and investment respond in the opposite direction.

The consumption preference shock in Poland leads to expansion in output, driven by higher consumption on the demand side and increased labour input on the supply side. Investment is crowded out. Following the appreciation of the exchange rate, inflation declines on impact and then rises, which causes a hike in interest rates. Given the perfect risk sharing structure of our model and positive cross correlation of the shocks, the response of the main macrovariables to the euro area consumption shock is qualitatively similar in both countries.

Following a negative labour supply shock in Poland, i.e. an increase in the weight of leisure in consumers' utility, labour input declines, which translates into lower consumption, investment and output. Growth in real wages leads to an increase in marginal costs and higher inflation, in response to which interest rates go up. Since the cross-country correlation of labour supply shocks is positive, the reaction of all major variables to the euro area labour supply shock is of the same direction in Poland and the euro area.

An unexpected rise in government spending leads to expansion in output and crowding out of private consumption and investment. ${ }^{19}$ Similarly as after the labour supply shock, the exchange rate appreciates,

\footnotetext{
${ }^{18}$ This should be also kept in mind while interpreting our estimates of near zero cross country correlation of productivity shocks in the tradable sector, which may be viewed as surprisingly low if compared to the standard parametrization used in the international business cycle literature (see Backus et al., 1992).

${ }^{19}$ It may be argued that the negative response of private consumption to an increase in government spending is inconsistent with the empirical evidence, indicating a positive comovement of both categories. In a DSGE framework, this effect can be
} 
causing a short-lived fall in inflation, the subsequent rise of which sparks reaction of the monetary authority. The government spending shock hitting the euro area causes positive comovements in the main macrovariables in both economies.

In response to an investment efficiency shock, output and investment expand. Initially negative reaction of consumption, accompanied by appreciation of the exchange rate, turns positive after about two years. Like in the case of other positive supply shocks, inflation declines. Again, the spillovers from the euro area investment efficiency shock are such that the response of the main variables in Poland is similar to that in the euro area.

The reaction to unexpected monetary policy tightening is standard. Declining consumption pushes down output, investment and labour input. The exchange rate appreciates, driving down inflation. Except for the initially positive impact of a surprise drop in inflation, real wages contract, leading to further price decline. Due to a relatively strong exchange rate channel, monetary contraction in the euro area has expansionary effects in Poland, though short-lived in terms of output and inflation.

\subsection{Empirical performance}

While obtaining the highest possible data fit was not the primary objective of building our model, it may be useful to take a look at two standard outputs of the estimation procedure obtained with the Kalman filter.

First, by applying a two-sided smoothing of the data we can obtain the time series for historical stochastic disturbances, identified given the model structure. These are plotted in Figure 17.

[Figure 17 about here]

A first look at the graphs confirms what we already stressed before: the magnitude of shocks hitting Poland is substantially larger than the size of shocks identified for the euro area. Focusing our attention on Poland, the estimates suggest that productivity in the tradable sector was relatively high in the middle of our sample and remained below average in the last three years. Roughly speaking, the opposite holds true for productivity in the nontradable sector and government spending shocks. Consumption preference and investment efficiency are clearly higher in the first part of our sample. ${ }^{20}$ Labour supply and monetary shocks do not exhibit such clear patterns, although the latter suggests a somewhat tighter monetary approach in the middle of our sample compared to more recent years. Given the unobservable nature of the stochastic processes, assessing the plausibility of their identification always involves a great deal of subjectivity. Therefore, we stop at this stage and do not attempt to link the evolution of the shocks to selected events and processes documented for the two economies.

The second popular and simple tool to assess the empirical performance of a DSGE model is to cast its one-side Kalman filter predictions of the observable variables against their realizations (see Figure 18).

[Figure 18 about here]

Concentrating again on the results for Poland, our model does a good job at tracking interest rates and inflation. Clearly, the model fails to account for the sharp and persistent slowdown in the economy in the middle of our sample and to capture volatility in real wage growth. All in all, the overall in-sample fit of our model seems to be acceptable if one takes into account a highly restrictive nature of the DSGE framework. It is worth noting that the empirical performance of our model seems to be significantly better in the last years of the sample. This is particularly true for GDP, consumption and real wage growth.

\section{Testing sources of heterogeneity}

In order to assess the degree of heterogeneity between Poland and the euro area in a more formal way, we estimate several restricted versions of our model and compare it to its fully-fledged, unrestricted specification. As indicated in the introduction, the Bayesian approach to estimation provides a natural platform for

\footnotetext{
obtained by assuming that a sufficiently large share of consumers behaves in a non-Ricardian way (see e.g. Gali et al., 2007). A less popular alternative is to allow for so-called deep habits in government spending (see Ravn et al., 2006).

${ }^{20}$ Consumption preference and investment efficiency shocks in our model have their relatively close counterparts in SOE-PL, which is a small open economy model developed by Adolfson et al. (2005) and estimated on the Polish data by Grabek et al. (2007). It is quite reassuring that the evolution in time of these disturbances roughly coincides in the two models.
} 
comparisons across potentially misspecified models. ${ }^{21}$ Formally, this can be done by assigning prior probabilities to competing models and then using the Bayes' theorem to see how probable each model is given the data. Taking the ratio of the posterior probability for a given model to that of the reference model gives the posterior odds on the latter. In practice, the prior probabilities of each competing model are often assumed to be the same, in which case the posterior odds reduce to the Bayes factor, defined as the ratio of marginal likelihoods (see formula (59)) of the competing models. ${ }^{22}$

Calculating the marginal likelihood of a model is far from straightforward. There are two popular approaches to this problem (see Schorfheide, 2002). First, one can assume that the posterior kernel shape is close to normal, which yields the so-called Laplace approximation. The other method, typically referred to as the harmonic mean estimator, relies on simulating the marginal density function using the algorithm developed by Geweke (1999). The clear advantage of the former technique is its computational efficiency: all what is needed is the posterior maximization, while the harmonic mean estimator needs running the time-consuming Metropolis-Hastings algorithm. Since the number of restrictions we want to test is rather large, we calculate the marginal likelihood of various versions of our model using the Laplace approximation. ${ }^{23}$

Our strategy to testing the sources of heterogeneity between Poland and the euro area can be described as follows. In the first step, we test for cross country differences parameter by parameter. ${ }^{24}$ Next we consider several tests of multiple hypotheses. The results are reported in Table 10.

\section{[Table 10 about here]}

In what follows, we base our inference on the scheme suggested by Kass and Raftery (1995), which is a modification of classical rules laid down by Jeffreys (1961). In particular, if the Bayes factor with respect to the unrestricted model is lower than $1 / 3(1 / 20,1 / 150)$, we treat it as positive (strong, very strong) evidence for heterogeneity between Poland and the euro area. It has to be noted that the marginal likelihood penalizes the model fit by a measure of its complexity. It means that it is perfectly possible that a restricted model will score better compared to its unrestricted version. In this case, the evidence in favour of homogeneity is judged in a symmetric fashion to that described above, with the cut-off points at 3, 20 and 150 .

Given these inference rules and starting from simple hypotheses, we do not find strong evidence neither for nor against homogeneity in structural parameters and shock inertia coefficients. The only exception is the degree of interest rate smoothing, which is significantly different between Poland and the euro area. This is mostly due to the fact that these parameters are estimated with relatively low precision. On the contrary, our results speak strongly or very strongly in favour of heterogeneity in volatilities of most shock processes. Only in the case of nontradable sector productivity and labour supply shocks is the evidence for heterogeneity weak, despite substantial differences in point estimates. Finally, all simple hypotheses of nearly perfect cross-country shock correlations are very strongly rejected by the data.

Turning to multiple hypotheses, our results speak strongly for structural homogeneity across Poland and the euro area: the model restricting the structural parameters (excluding the parametrization of the monetary policy reaction function) to be equal in both economies fits the data significantly better than a model assuming that all of them are different. Despite strong evidence in favour of heterogeneity between interest rate smoothing pointed out above, the model assuming identical monetary policy feedback rules in Poland and in the euro area turns out to be as good as our baseline specification. Our results speak strongly against full stochastic homogeneity: shock volatilities differ across countries in a significant way and they are very far from being perfectly synchronized. It has to be noted that lack of cross correlation of stochastic disturbances is rejected by the data as well, although not as strongly as the perfect correlation hypothesis. Hence, our results should be viewed as suggesting moderate interdependence of shocks between Poland and the euro area.

\footnotetext{
${ }^{21}$ See e.g. Landon-Lane (1998).

${ }^{22}$ Since the marginal likelihood of a model is directly related to the predictive density of the model, it provides a natural platform for model comparisons based on the data fit. See e.g. Lancaster (2004).

${ }^{23}$ As a robustness check, we assess the marginal data density for our key restricted specifications using the harmonic mean estimator. The conclusions one can draw from comparing them to the unrestricted version are qualitatively the same as those obtained using the Laplace approximation.

${ }^{24}$ Testing for perfect synchronization of shocks cannot be done in a straightforward manner, since imposing a unity restriction on any cross correlation effectively reduces the number of shocks, which leads to a well-known problem of stochastic singularity, as long as all observable variables are used in the estimation. To deal with this problem, we approximate the synchronized versions of our model by setting cross correlations of the relevant shocks to 0.95 .
} 


\section{Conclusions}

The main objective of this paper was to build a two-country model linking Poland and the euro area and to apply it for assessment of heterogeneity across these two regions. Overall, our results can be seen as rather inconclusive about the differences in parameters driving behaviour of agents in Poland and the euro area. On the contrary, we find strong evidence for heterogeneity in terms of volatility and synchronization of shocks hitting both economies.

Our results suggest that a policy optimal for the euro area might not be optimal for Poland. This means that Poland's entry to the EMU will involve costs associated with losing the monetary autonomy and stabilizing movements of the exchange rate. It is somewhat reassuring, however, that the detected extent of heterogeneity in terms of imperfect cross country correlation of stochastic disturbances is not very different from that obtained in studies covering relatively closely integrated euro area member states.

It should also be noted that the welfare losses associated with imperfect synchronization of shocks are usually found to be of small magnitude (see e.g. Corsetti, 2008). Nevertheless, a careful examination of such costs definitely warrants attention. A flexible design of our model makes it a good workhorse for comparing alternative monetary regimes, including the fixed exchange rate regime. We leave these interesting questions for future research. 


\section{References}

Adolfson, M., Laseén, S., Lindé, J., Villani, M. (2005). Bayesian Estimation of an Open Economy DSGE Model with Incomplete Pass-Through, Sveriges Riksbank Working Paper No. 179.

Altissimo, F., Ehrmann, M., Smets, F. (2006). Inflation persistence and price-setting behaviour in the euro area: A summary of the IPN evidence, ECB Occasional Paper Series 46.

An, S., Schorfheide, F. (2007). Bayesian Analysis of DSGE Models, Econometric Reviews 26(2-4): 113172 .

Backus, D.K., Kehoe, P.J., Kydland, F.E. (1992). International Real Business Cycles, Journal of Political Economy 100: 745-775.

Benigno, G., Thoenissen, C. (2003). Equilibrium Exchange Rates and Supply-Side Performance, Economic Journal 113(486): C103-C124.

Bergin, P. (2003). Putting the 'New Open Economy Macroeconomics' to a test, Journal of International Economics 60: 3-34.

Botman, D., Karam, P., Laxton, D., Rose, D. (2007). DSGE Modeling at the Fund: Applications and Further Developments, IMF Working Paper 07/200.

Botman, D., Laxton, D., Muir, D., Romanov, A. (2006). A New-Open-Economy-Macro Model for Fiscal Policy Evaluation, IMF Working Paper 06/045.

Brooks, S.P., Gelman, A. (1998). General Methods for Monitoring Convergence of Iterative Simulations, Journal of Computational and Graphical Statistics 7(4): 434-455.

Burstein, A.T., Neves, J.C., Rebelo, S. (2003). Distribution costs and real exchange rate dynamics during exchange-rate-based stabilizations, Journal of Monetary Economics 50: 1189-1214.

Calvo, G. (1983). Staggered Prices in a Utility-Maximizing Framework, Journal of Monetary Economics 12: 383-398.

Canova, F. (2007). Methods for Applied Macroeconomic Research, Princeton University Press.

Chari, V.V., Kehoe, P., McGrattan, E. (2002). Can Sticky Price Models Generate Volatile and Persistent Real Exchange Rates? Review of Economic Studies 69: 533-563.

Chib, S., Greenberg, E. (1995). Understanding the Metropolis-Hastings Algorithm, American Statistician 49(4): 327-335.

Christiano, L., Eichenbaum, M., Evans, C. (2005). Nominal Rigidities and the Dynamic Effects of a Shock to Monetary Policy, Journal of Political Economy 113(1): 1-45.

Corsetti, G. (2008). A Modern Reconsideration of the Theory of Optimal Currency Areas, EUI Working Paper No. 2008/12, European University Institute.

Corsetti, G., Dedola, L. (2005). A macroeconomic model of international price discrimination, Journal of International Economics 67: 129-155.

de Walque, G., Wouters, R. (2004). An Open Economy DSGE Model Linking the Euro Area and the US Economy, paper presented at the Bundesbank conference "SDGE models and the financial sector", Eltville.

Erceg, C.J., Henderson, D.W., Levin, A.T. (2000). Optimal monetary policy with staggered wage and price contracts, Journal of Monetary Economics 46: 281-313.

Erceg, C.J., Levin, A. (1996). Structures And The Dynamic Behavior Of The Real Exchange Rate, mimeo, Board of Governors of the Federal Reserve.

Fernandez-Villaverde, J., Rubio-Ramirez, J.F. (2004). Comparing dynamic equilibrium models to data: a Bayesian approach, Journal of Econometrics 123: 153-187.

Gali, J. (1999). Technology, Employment, and the Business Cycle: Do Technology Shocks Explain Aggregate Fluctuations? American Economic Review 89(1): 249-271.

Gali, J., Lopez-Salido, J.D., Valles, J. (2007). Understanding the Effects of Government Spending on Consumption, Journal of the European Economic Association 5(1): 227-270.

Gali, J., Monacelli, T. (2005). Monetary Policy and Exchange Rate Volatility in a Small Open Economy, Review of Economic Studies 72(3): 707-734. 
Geweke, J. (1999). Using simulation methods for Bayesian econometric models: inference, development and communication, Econometric Reviews 18: 1-126.

Grabek, G., Kłos, B., Utzig-Lenarczyk, G. (2007). SOE-PL - model DSGE małej otwartej gospodarki estymowany na danych polskich, Materiały i Studia No. 217, NBP.

Jeffreys, H. (1961). Theory of Probability, Oxford University Press, Oxford UK.

Jondeau, E., Sahuc, J-G. (2005). Testing Heterogeneity within the Euro Area Using a Structural MultiCountry Model, EABCN.

Kass, R.E., Raftery, A.E. (1995). Bayes Factors, Journal of the American Statistical Association 90: 773-795.

Lancaster, T. (2004). An Introduction to Modern Bayesian Econometrics, Blackwell Publishing, Oxford UK.

Landon-Lane, J. (1998). Bayesian comparison of dynamic macroeconomic models, Ph.D. Thesis, University of Minnesota.

Lane, P.R. (2001). The new open economy macroeconomics: a survey, Journal of International Economics 54: $235-266$.

Laxton, D., Pesenti, P. (2003). Monetary rules for small, open, emerging economies, Journal of Monetary Economics 50: 1109-1146.

Lubik, T., Schorfheide, F. (2006). A Bayesian Look at New Open Economy Macroeconomics, in: Gertler, M., Rogoff, K. [eds.], NBER Macroeconomics Annual 2005, MIT Press, Cambridge MA.

Mundell, R. (1961). A Theory of Optimum Currency Areas, American Economic Review 51: 657-664.

Obstfeld, M., Rogoff, K. (1995). Exchange rate dynamics redux, Journal of Political Economy 103: 624-660.

Obstfeld, M., Rogoff, K. (2000). New directions for stochastic open economy models, Journal of International Economics 50: 117-153.

Onatski, A., Williams, N. (2004). Empirical and policy performance of a forward-looking monetary model, Proceedings, Federal Reserve Bank of San Francisco.

Pytlarczyk, E. (2005). An estimated DSGE model for the German economy within the euro area, Discussion Paper Series 1: Economic Studies 2005, 33, Deutsche Bundesbank.

Sims, C. (2002). Solving Linear Rational Expectations Models, Computational Economics 20(1-2): 1-20.

Rabanal, P. (2007). Inflation Differentials in a Currency Union: A DSGE Perspective, La Caixa Working Paper No. 6.

Rabanal, P., Rubio-Ramirez, J.F. (2005). Comparing New Keynesian models of the business cycle: A Bayesian approach, Journal of Monetary Economics 52: 1151-1166.

Ravn, M., Schmitt-Grohe, S., Uribe, M. (2006). Deep Habits, Review of Economic Studies 73(1): 195-218.

Schorfheide, F. (2002). Loss function-based evaluation of DSGE models, Journal of Applied Econometrics 15: $645-670$.

Smets, F., Wouters, R. (2003). An Estimated Stochastic Dynamic General Equilibrium Model for the Euro Area, Journal of the European Economic Association 1(5): 1123-1175.

Tower, E., Willett, T. (1976). The Theory of Optimum Currency Areas and Exchange-rates Flexibility, Princeton University Press, Princeton: NJ.

Warnock, F.E. (1998). Idiosyncratic tastes in a two-country optimizing model: implications of a standard presumption, International Finance Discussion Papers 631, Board of Governors of the Federal Reserve. 


\section{Tables and figures}

Table 1. Estimation results: structural parameters

\begin{tabular}{l|ccc|c|c|ccc} 
& \multicolumn{3}{|c|}{ Prior distribution } & \multicolumn{3}{c|}{ Posterior max. } & \multicolumn{3}{c}{ Posterior distribution } \\
& type & mean & st. error & mode & st. error & $5 \%$ & mean & $95 \%$ \\
\hline$h$ & beta & 0.7 & 0.1 & 0.800 & 0.065 & 0.699 & 0.797 & 0.901 \\
$h^{*}$ & beta & 0.7 & 0.1 & 0.642 & 0.091 & 0.510 & 0.646 & 0.780 \\
$\sigma$ & gamma & 1.5 & 0.4 & 1.799 & 0.405 & 1.266 & 1.945 & 2.657 \\
$\sigma^{*}$ & gamma & 1.5 & 0.4 & 1.774 & 0.373 & 1.279 & 1.910 & 2.571 \\
$\varphi$ & gamma & 2.0 & 0.4 & 1.936 & 0.328 & 1.451 & 2.014 & 2.589 \\
$\varphi^{*}$ & gamma & 2.0 & 0.4 & 1.820 & 0.351 & 1.333 & 1.915 & 2.480 \\
$S^{\prime \prime}$ & normal & 4.0 & 1.5 & 5.185 & 1.211 & 3.542 & 5.445 & 7.343 \\
$S^{\prime \prime *}$ & normal & 4.0 & 1.5 & 5.424 & 1.186 & 3.756 & 5.759 & 7.636 \\
$\delta_{H}$ & beta & 0.5 & 0.2 & 0.171 & 0.131 & 0.042 & 0.276 & 0.513 \\
$\delta_{F}^{*}$ & beta & 0.5 & 0.2 & 0.146 & 0.110 & 0.037 & 0.209 & 0.389 \\
$\delta_{N}$ & beta & 0.5 & 0.2 & 0.103 & 0.075 & 0.020 & 0.162 & 0.295 \\
$\delta_{N}^{*}$ & beta & 0.5 & 0.2 & 0.089 & 0.070 & 0.017 & 0.162 & 0.298 \\
$\delta_{W}$ & beta & 0.5 & 0.2 & 0.334 & 0.167 & 0.124 & 0.383 & 0.634 \\
$\delta_{W}^{*}$ & beta & 0.5 & 0.2 & 0.141 & 0.063 & 0.051 & 0.157 & 0.253 \\
$\theta_{H}$ & beta & 0.7 & 0.1 & 0.533 & 0.079 & 0.435 & 0.552 & 0.678 \\
$\theta_{F}^{*}$ & beta & 0.7 & 0.1 & 0.477 & 0.078 & 0.367 & 0.485 & 0.610 \\
$\theta_{N}$ & beta & 0.7 & 0.1 & 0.793 & 0.043 & 0.713 & 0.786 & 0.863 \\
$\theta_{N}^{*}$ & beta & 0.7 & 0.1 & 0.754 & 0.036 & 0.694 & 0.752 & 0.813 \\
$\theta_{W}$ & beta & 0.7 & 0.1 & 0.598 & 0.055 & 0.533 & 0.621 & 0.707 \\
$\theta_{W}^{*}$ & beta & 0.7 & 0.1 & 0.735 & 0.045 & 0.683 & 0.752 & 0.824 \\
$\rho$ & beta & 0.7 & 0.1 & 0.787 & 0.026 & 0.746 & 0.787 & 0.830 \\
$\rho^{*}$ & beta & 0.7 & 0.1 & 0.899 & 0.016 & 0.872 & 0.899 & 0.925 \\
$\phi_{y}$ & gamma & 0.5 & 0.1 & 0.258 & 0.040 & 0.202 & 0.270 & 0.337 \\
$\phi_{y}^{*}$ & gamma & 0.5 & 0.1 & 0.214 & 0.043 & 0.153 & 0.229 & 0.305 \\
$\phi_{\pi}$ & gamma & 2.0 & 0.2 & 2.122 & 0.170 & 1.859 & 2.128 & 2.400 \\
$\phi_{\pi}^{*}$ & gamma & 2.0 & 0.2 & 2.214 & 0.205 & 1.864 & 2.213 & 2.538 \\
& & & & & & & &
\end{tabular}


Table 2. Estimation results: shocks

\begin{tabular}{|c|c|c|c|c|c|c|c|c|}
\hline & \multicolumn{3}{|c|}{ Prior distribution } & \multicolumn{2}{|c|}{ Posterior max. } & \multicolumn{3}{|c|}{ Posterior distribution } \\
\hline & type & mean & st. error & mode & st. error & $5 \%$ & mean & $95 \%$ \\
\hline$\rho_{a^{H}}$ & beta & 0.7 & 0.1 & 0.788 & 0.063 & 0.633 & 0.749 & 0.867 \\
\hline$\rho_{a^{F}}^{*}$ & beta & 0.7 & 0.1 & 0.634 & 0.098 & 0.460 & 0.616 & 0.775 \\
\hline$\rho_{a^{N}}$ & beta & 0.7 & 0.1 & 0.939 & 0.030 & 0.873 & 0.923 & 0.977 \\
\hline$\rho_{a^{N}}^{*}$ & beta & 0.7 & 0.1 & 0.732 & 0.094 & 0.553 & 0.698 & 0.848 \\
\hline$\rho_{d}$ & beta & 0.7 & 0.1 & 0.679 & 0.082 & 0.531 & 0.664 & 0.785 \\
\hline$\rho_{d}^{*}$ & beta & 0.7 & 0.1 & 0.660 & 0.085 & 0.519 & 0.647 & 0.783 \\
\hline$\rho_{l}$ & beta & 0.7 & 0.1 & 0.546 & 0.096 & 0.396 & 0.540 & 0.694 \\
\hline$\rho_{l}^{*}$ & beta & 0.7 & 0.1 & 0.621 & 0.084 & 0.484 & 0.621 & 0.751 \\
\hline$\rho_{g}$ & beta & 0.7 & 0.1 & 0.838 & 0.036 & 0.774 & 0.832 & 0.892 \\
\hline$\rho_{g}^{*}$ & beta & 0.7 & 0.1 & 0.841 & 0.055 & 0.744 & 0.829 & 0.918 \\
\hline$\rho_{i}$ & beta & 0.7 & 0.1 & 0.754 & 0.047 & 0.662 & 0.739 & 0.819 \\
\hline$\rho_{i}^{*}$ & beta & 0.7 & 0.1 & 0.710 & 0.059 & 0.602 & 0.696 & 0.794 \\
\hline$\sigma_{a^{H}}$ & inv. gamma & 9.0 & $\inf$ & 6.339 & 1.719 & 4.503 & 8.132 & 11.910 \\
\hline$\sigma_{a^{F}}^{*}$ & inv. gamma & 3.0 & inf & 1.789 & 0.477 & 1.202 & 2.078 & 2.937 \\
\hline$\sigma_{a^{N}}$ & inv. gamma & 4.5 & $\inf$ & 2.096 & 0.465 & 1.555 & 2.420 & 3.297 \\
\hline$\sigma_{a^{N}}^{*}$ & inv. gamma & 1.5 & $\inf$ & 0.767 & 0.196 & 0.531 & 0.905 & 1.270 \\
\hline$\sigma_{d}$ & inv. gamma & 9.0 & $\inf$ & 7.879 & 2.195 & 5.025 & 9.176 & 13.244 \\
\hline$\sigma_{d}^{*}$ & inv. gamma & 3.0 & $\inf$ & 2.031 & 0.513 & 1.453 & 2.341 & 3.278 \\
\hline$\sigma_{l}$ & inv. gamma & 18.0 & $\inf$ & 12.705 & 4.362 & 7.765 & 16.623 & 25.362 \\
\hline$\sigma_{l}^{*}$ & inv. gamma & 6.0 & $\inf$ & 4.157 & 1.445 & 2.563 & 5.501 & 8.490 \\
\hline$\sigma_{g}$ & inv. gamma & 6.0 & $\inf$ & 5.743 & 0.609 & 4.998 & 6.050 & 7.104 \\
\hline$\sigma_{g}^{*}$ & inv. gamma & 2.0 & $\inf$ & 1.169 & 0.119 & 1.005 & 1.217 & 1.419 \\
\hline$\sigma_{i}^{g}$ & inv. gamma & 9.0 & $\inf$ & 8.124 & 1.730 & 6.035 & 9.035 & 11.962 \\
\hline$\sigma_{i}^{*}$ & inv. gamma & 3.0 & $\inf$ & 2.119 & 0.463 & 1.596 & 2.385 & 3.168 \\
\hline$\sigma_{m}$ & inv. gamma & 0.3 & $\inf$ & 0.265 & 0.031 & 0.223 & 0.276 & 0.326 \\
\hline$\sigma_{m}^{*}$ & inv. gamma & 0.1 & $\inf$ & 0.082 & 0.009 & 0.068 & 0.085 & 0.101 \\
\hline $\operatorname{corr}_{a^{H, F}}$ & normal & 0.0 & 0.4 & 0.013 & 0.142 & -0.234 & -0.006 & 0.231 \\
\hline $\operatorname{corr}_{a^{N}}$ & normal & 0.0 & 0.4 & -0.333 & 0.127 & -0.506 & -0.307 & -0.095 \\
\hline $\operatorname{corr}_{d}$ & normal & 0.0 & 0.4 & 0.329 & 0.126 & 0.105 & 0.309 & 0.512 \\
\hline $\operatorname{corr}_{l}$ & normal & 0.0 & 0.4 & 0.285 & 0.138 & 0.051 & 0.269 & 0.492 \\
\hline $\operatorname{corr}_{g}$ & normal & 0.0 & 0.4 & 0.128 & 0.136 & -0.089 & 0.122 & 0.348 \\
\hline $\operatorname{corr}_{i}$ & normal & 0.0 & 0.4 & 0.356 & 0.126 & 0.136 & 0.341 & 0.547 \\
\hline $\operatorname{corr}_{m}$ & normal & 0.0 & 0.4 & -0.049 & 0.147 & -0.270 & -0.045 & 0.183 \\
\hline
\end{tabular}


Table 3. Variance decomposition - output

\begin{tabular}{l|cccc} 
Shocks & $1 \mathrm{Q}$ & $4 \mathrm{Q}$ & $8 \mathrm{Q}$ & $100 \mathrm{Q}$ \\
\hline Productivity shock in tradables - Poland & 26.1 & 30.8 & 21.5 & 11.5 \\
Productivity shock in tradables - euro area & 0.5 & 0.2 & 0.1 & 0.1 \\
Productivity shock in nontradables - Poland & 14.2 & 27.9 & 40.7 & 53.9 \\
Productivity shock in nontradables - euro area & 2.0 & 3.2 & 4.3 & 5.7 \\
Consumption preference shock - Poland & 3.5 & 4.4 & 2.8 & 1.7 \\
Consumption preference shock - euro area & 1.0 & 0.8 & 0.5 & 0.3 \\
Labour supply shock - Poland & 1.4 & 2.7 & 2.8 & 1.7 \\
Labour supply shock - euro area & 0.1 & 0.2 & 0.2 & 0.1 \\
Government spending shock - Poland & 39.2 & 11.1 & 6.0 & 3.3 \\
Government spending shock - euro area & 0.8 & 0.2 & 0.1 & 0.1 \\
Investment efficiency shock - Poland & 6.7 & 14.6 & 17.5 & 18.7 \\
Investment efficiency shock - euro area & 1.5 & 2.6 & 2.7 & 2.5 \\
Monetary policy shock - Poland & 2.8 & 1.1 & 0.7 & 0.4 \\
Monetary policy shock - euro area & 0.3 & 0.1 & 0.0 & 0.0
\end{tabular}

Table 4. Variance decomposition - consumption

\begin{tabular}{l|cccc} 
Shocks & $1 \mathrm{Q}$ & $4 \mathrm{Q}$ & $8 \mathrm{Q}$ & $100 \mathrm{Q}$ \\
\hline Productivity shock in tradables - Poland & 0.8 & 2.2 & 2.6 & 1.5 \\
Productivity shock in tradables - euro area & 0.1 & 0.2 & 0.2 & 0.1 \\
Productivity shock in nontradables - Poland & 1.8 & 6.4 & 14.2 & 33.5 \\
Productivity shock in nontradables - euro area & 0.1 & 0.6 & 1.4 & 3.4 \\
Consumption preference shock - Poland & 87.1 & 80.2 & 71.1 & 39.4 \\
Consumption preference shock - euro area & 8.4 & 7.4 & 6.4 & 3.6 \\
Labour supply shock - Poland & 0.1 & 0.4 & 0.7 & 0.6 \\
Labour supply shock - euro area & 0.0 & 0.1 & 0.1 & 0.1 \\
Government spending shock - Poland & 0.6 & 1.2 & 1.9 & 1.8 \\
Government spending shock - euro area & 0.0 & 0.0 & 0.1 & 0.1 \\
Investment efficiency shock - Poland & 0.3 & 0.7 & 0.7 & 13.1 \\
Investment efficiency shock - euro area & 0.1 & 0.2 & 0.2 & 2.6 \\
Monetary policy shock - Poland & 0.5 & 0.4 & 0.3 & 0.2 \\
Monetary policy shock - euro area & 0.0 & 0.0 & 0.0 & 0.0
\end{tabular}


Table 5. Variance decomposition - investment

\begin{tabular}{l|cccc} 
Shocks & $1 \mathrm{Q}$ & $4 \mathrm{Q}$ & $8 \mathrm{Q}$ & $100 \mathrm{Q}$ \\
\hline Productivity shock in tradables - Poland & 0.6 & 0.6 & 0.4 & 0.3 \\
Productivity shock in tradables - euro area & 0.1 & 0.1 & 0.0 & 0.0 \\
Productivity shock in nontradables - Poland & 6.6 & 14.0 & 23.4 & 36.0 \\
Productivity shock in nontradables - euro area & 0.7 & 1.5 & 2.6 & 4.0 \\
Consumption preference shock - Poland & 1.1 & 1.9 & 2.8 & 3.1 \\
Consumption preference shock - euro area & 0.2 & 0.4 & 0.4 & 0.4 \\
Labour supply shock - Poland & 0.4 & 0.8 & 0.9 & 0.8 \\
Labour supply shock - euro area & 0.1 & 0.1 & 0.1 & 0.1 \\
Government spending shock - Poland & 1.0 & 1.5 & 1.8 & 1.8 \\
Government spending shock - euro area & 0.0 & 0.0 & 0.0 & 0.0 \\
Investment efficiency shock - Poland & 79.6 & 70.9 & 60.5 & 48.1 \\
Investment efficiency shock - euro area & 9.3 & 8.0 & 6.7 & 5.3 \\
Monetary policy shock - Poland & 0.4 & 0.3 & 0.2 & 0.1 \\
Monetary policy shock - euro area & 0.0 & 0.0 & 0.0 & 0.0
\end{tabular}

Table 6. Variance decomposition - real wage rate

\begin{tabular}{l|cccc} 
Shocks & $1 \mathrm{Q}$ & $4 \mathrm{Q}$ & $8 \mathrm{Q}$ & $100 \mathrm{Q}$ \\
\hline Productivity shock in tradables - Poland & 23.3 & 17.7 & 10.8 & 3.5 \\
Productivity shock in tradables - euro area & 2.1 & 0.9 & 0.5 & 0.1 \\
Productivity shock in nontradables - Poland & 5.5 & 23.9 & 45.1 & 59.2 \\
Productivity shock in nontradables - euro area & 0.2 & 2.1 & 4.6 & 6.1 \\
Consumption preference shock - Poland & 1.1 & 0.3 & 0.2 & 0.6 \\
Consumption preference shock - euro area & 0.0 & 0.0 & 0.0 & 0.1 \\
Labour supply shock - Poland & 57.7 & 44.6 & 25.0 & 7.9 \\
Labour supply shock - euro area & 3.8 & 2.8 & 1.5 & 0.5 \\
Government spending shock - Poland & 1.9 & 0.6 & 0.3 & 0.4 \\
Government spending shock - euro area & 0.0 & 0.0 & 0.0 & 0.0 \\
Investment efficiency shock - Poland & 3.3 & 5.9 & 10.3 & 18.1 \\
Investment efficiency shock - euro area & 0.2 & 0.6 & 1.3 & 3.2 \\
Monetary policy shock - Poland & 0.5 & 0.3 & 0.3 & 0.1 \\
Monetary policy shock - euro area & 0.4 & 0.1 & 0.0 & 0.0
\end{tabular}


Table 7. Variance decomposition - real exchange rate

\begin{tabular}{l|cccc} 
Shocks & $1 \mathrm{Q}$ & $4 \mathrm{Q}$ & $8 \mathrm{Q}$ & $100 \mathrm{Q}$ \\
\hline Productivity shock in tradables - Poland & 15.5 & 13.8 & 9.6 & 4.4 \\
Productivity shock in tradables - euro area & 0.0 & 0.1 & 0.1 & 0.0 \\
Productivity shock in nontradables - Poland & 35.2 & 46.8 & 54.5 & 53.8 \\
Productivity shock in nontradables - euro area & 7.5 & 10.1 & 10.6 & 8.5 \\
Consumption preference shock - Poland & 10.2 & 9.3 & 9.4 & 5.5 \\
Consumption preference shock - euro area & 0.1 & 0.1 & 0.1 & 0.1 \\
Labour supply shock - Poland & 2.2 & 3.0 & 2.7 & 1.4 \\
Labour supply shock - euro area & 0.0 & 0.0 & 0.0 & 0.0 \\
Government spending shock - Poland & 10.8 & 8.0 & 6.9 & 3.8 \\
Government spending shock - euro area & 0.0 & 0.0 & 0.0 & 0.0 \\
Investment efficiency shock - Poland & 6.2 & 4.4 & 3.2 & 20.6 \\
Investment efficiency shock - euro area & 0.4 & 0.3 & 0.2 & 0.7 \\
Monetary policy shock - Poland & 8.9 & 2.8 & 1.8 & 0.8 \\
Monetary policy shock - euro area & 3.0 & 1.2 & 0.8 & 0.4
\end{tabular}

Table 8. Variance decomposition - inflation

\begin{tabular}{l|cccc} 
Shocks & $1 \mathrm{Q}$ & $4 \mathrm{Q}$ & $8 \mathrm{Q}$ & $100 \mathrm{Q}$ \\
\hline Productivity shock in tradables - Poland & 63.7 & 43.6 & 36.2 & 25.7 \\
Productivity shock in tradables - euro area & 2.1 & 1.1 & 0.9 & 0.7 \\
Productivity shock in nontradables - Poland & 23.5 & 42.9 & 49.1 & 53.4 \\
Productivity shock in nontradables - euro area & 1.6 & 4.1 & 5.0 & 5.5 \\
Consumption preference shock - Poland & 0.4 & 0.4 & 0.4 & 0.5 \\
Consumption preference shock - euro area & 0.0 & 0.1 & 0.1 & 0.1 \\
Labour supply shock - Poland & 3.2 & 4.7 & 4.2 & 3.0 \\
Labour supply shock - euro area & 0.4 & 0.5 & 0.5 & 0.3 \\
Government spending shock - Poland & 0.1 & 0.2 & 0.2 & 0.3 \\
Government spending shock - euro area & 0.1 & 0.0 & 0.0 & 0.0 \\
Investment efficiency shock - Poland & 0.6 & 0.4 & 1.6 & 8.3 \\
Investment efficiency shock - euro area & 0.0 & 0.0 & 0.1 & 1.0 \\
Monetary policy shock - Poland & 3.8 & 1.8 & 1.5 & 1.1 \\
Monetary policy shock - euro area & 0.5 & 0.2 & 0.2 & 0.1
\end{tabular}




\section{Table 9. Variance decomposition - interest rate}

\begin{tabular}{l|cccc} 
Shocks & $1 \mathrm{Q}$ & $4 \mathrm{Q}$ & $8 \mathrm{Q}$ & $100 \mathrm{Q}$ \\
\hline Productivity shock in tradables - Poland & 49.2 & 37.5 & 25.4 & 16.0 \\
Productivity shock in tradables - euro area & 2.5 & 1.4 & 0.9 & 0.6 \\
Productivity shock in nontradables - Poland & 17.1 & 40.9 & 52.9 & 58.3 \\
Productivity shock in nontradables - euro area & 1.0 & 3.5 & 5.2 & 6.1 \\
Consumption preference shock - Poland & 0.1 & 1.1 & 2.2 & 2.1 \\
Consumption preference shock - euro area & 0.2 & 0.5 & 0.6 & 0.5 \\
Labour supply shock - Poland & 2.5 & 4.8 & 4.5 & 2.9 \\
Labour supply shock - euro area & 0.3 & 0.6 & 0.6 & 0.4 \\
Government spending shock - Poland & 0.7 & 2.3 & 2.5 & 1.9 \\
Government spending shock - euro area & 0.2 & 0.2 & 0.1 & 0.1 \\
Investment efficiency shock - Poland & 0.1 & 0.6 & 0.9 & 7.7 \\
Investment efficiency shock - euro area & 0.1 & 0.5 & 0.6 & 1.4 \\
Monetary policy shock - Poland & 25.9 & 6.0 & 3.6 & 2.3 \\
Monetary policy shock - euro area & 0.2 & 0.1 & 0.0 & 0.0
\end{tabular}


Table 10. Testing sources of heterogeneity

\begin{tabular}{|c|c|c|c|}
\hline No. & Hypothesis & Log marginal data density & Bayes factor \\
\hline 0 & unrestricted model & -439.7 & 1.000 \\
\hline 1 & $h=h^{*}$ & -440.6 & 0.426 \\
\hline 2 & $\sigma=\sigma^{*}$ & -438.9 & 2.315 \\
\hline 3 & $\varphi=\varphi^{*}$ & -439.7 & 1.039 \\
\hline 4 & $S^{\prime \prime}=S^{\prime \prime *}$ & -438.8 & 2.489 \\
\hline 5 & $\delta_{H}=\delta_{F}^{*}$ & -438.3 & 4.033 \\
\hline 6 & $\delta_{N}=\delta_{N}^{*}$ & -437.2 & 12.944 \\
\hline 7 & $\delta_{W}=\delta_{W}^{*}$ & -439.2 & 1.673 \\
\hline 8 & $\theta_{H}=\theta_{F}^{*}$ & -437.7 & 7.568 \\
\hline 9 & $\theta_{N}=\theta_{N}^{*}$ & -439.1 & 1.756 \\
\hline 10 & $\theta_{W}=\theta_{W}^{*}$ & -440.8 & 0.354 \\
\hline 11 & $\rho=\rho^{*}$ & -444.6 & 0.008 \\
\hline 12 & $\phi_{y}=\phi_{y}^{*}$ & -441.4 & 0.188 \\
\hline 13 & $\phi_{\pi}=\phi_{\pi}^{*}$ & -439.2 & 1.633 \\
\hline 14 & $\rho_{a^{H}}=\rho_{a_{F}}^{*}$ & -440.3 & 0.532 \\
\hline 15 & $\rho_{a^{N}}=\rho_{a^{N}}^{*}$ & -439.9 & 0.857 \\
\hline 16 & $\rho_{d}=\rho_{d}^{*}$ & -439.5 & 1.278 \\
\hline 17 & $\rho_{l}=\rho_{l}^{*}$ & -438.8 & 2.385 \\
\hline 18 & $\rho_{q}=\rho_{q}^{*}$ & -438.4 & 3.872 \\
\hline 19 & $\rho_{i}=\rho_{i}^{*}$ & -439.4 & 1.323 \\
\hline 20 & $\sigma_{a^{H}}=\sigma_{a^{F}}^{*}$ & -444.5 & 0.008 \\
\hline 21 & $\sigma_{a^{N}}=\sigma_{a^{N}}^{a^{*}}$ & -442.2 & 0.085 \\
\hline 22 & $\sigma_{d}=\sigma_{d}^{*}$ & -445.3 & 0.004 \\
\hline 23 & $\sigma_{l}=\sigma_{l}^{*}$ & -441.2 & 0.227 \\
\hline 24 & $\sigma_{g}=\sigma_{g}^{*}$ & -486.4 & 0.000 \\
\hline 25 & $\sigma_{i}=\sigma_{i}^{*}$ & -449.4 & 0.000 \\
\hline 26 & $\sigma_{m}=\sigma_{m}^{*}$ & -461.0 & 0.000 \\
\hline 27 & $\operatorname{corr}_{a^{H, F}} \approx 1$ & -493.1 & 0.000 \\
\hline 28 & $\operatorname{corr}_{a^{N}} \approx 1$ & -510.1 & 0.000 \\
\hline 29 & $\operatorname{corr}_{d} \approx 1$ & -483.8 & 0.000 \\
\hline 30 & $\operatorname{corr}_{l} \approx 1$ & -476.2 & 0.000 \\
\hline 31 & $\operatorname{corr}_{g} \approx 1$ & -487.8 & 0.000 \\
\hline 32 & $\operatorname{corr}_{i} \approx 1$ & -473.1 & 0.000 \\
\hline 33 & $\operatorname{corr}_{m} \approx 1$ & -492.7 & 0.000 \\
\hline 34 & utility (1-3) & -439.7 & 1.007 \\
\hline 35 & price and wage formation $(5-10)$ & -434.6 & 174.469 \\
\hline 36 & structural $(1-10)$ & -433.8 & 380.615 \\
\hline 37 & policy reaction (11-13) & -438.9 & 2.320 \\
\hline 38 & shock inertia (14-19) & -437.6 & 8.536 \\
\hline 39 & shock volatility (20-26) & -527.3 & 0.000 \\
\hline 40 & shock inertia and volatility $(37-38)$ & -543.6 & 0.000 \\
\hline 41 & (nearly) perfect correlation of shocks (27-33) & $-9.2 \mathrm{E}+18$ & 0.000 \\
\hline 42 & stochastic homogeneity (39-41) & -38034.8 & 0.000 \\
\hline 43 & no correlation of shocks & -443.0 & 0.036 \\
\hline
\end{tabular}


Figure 1. Prior and posterior densities - parameters
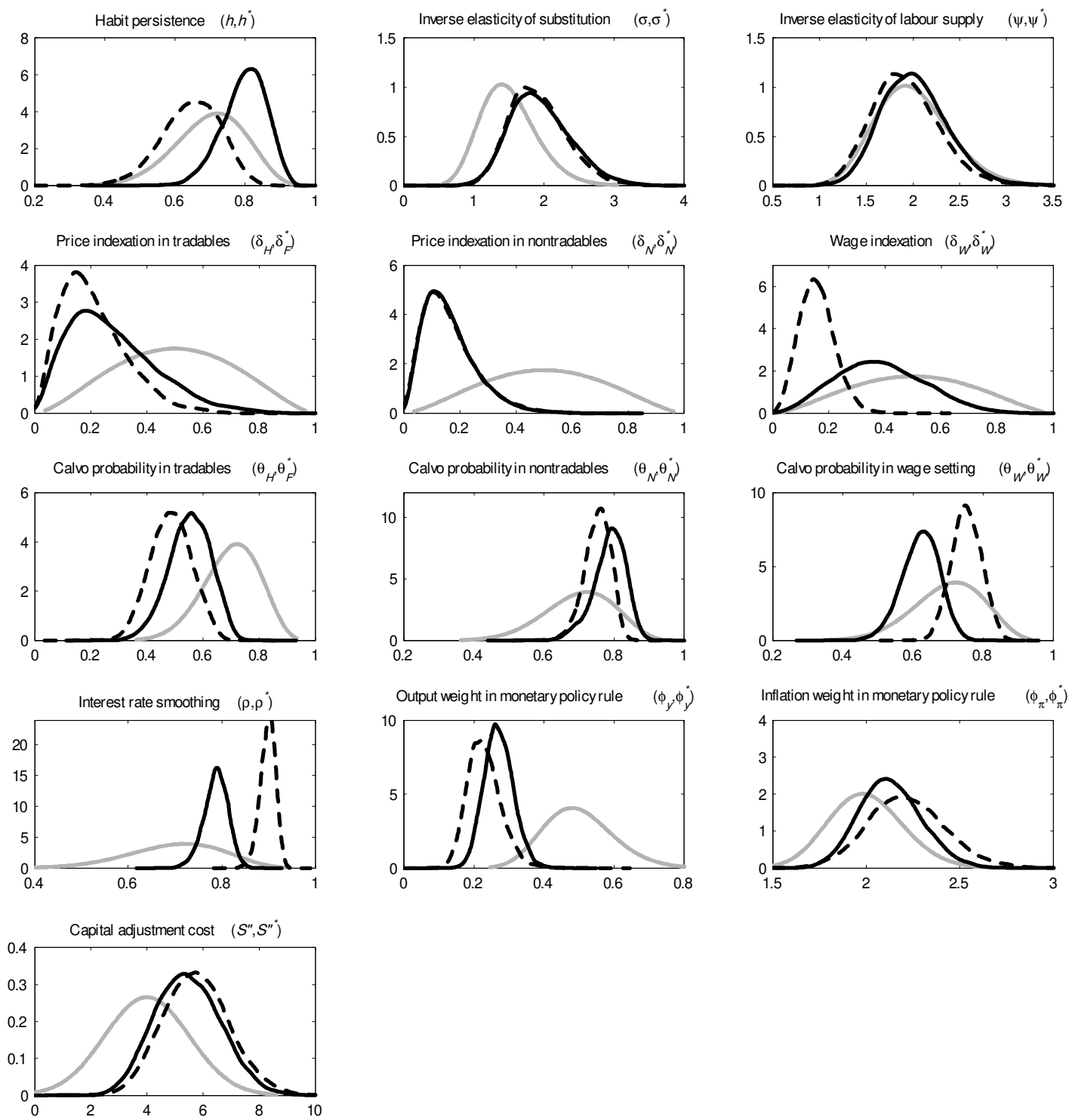

Note: grey solid line - prior distributions, black solid line - posterior for Poland, dashed solid line posterior for the euro area. 
Figure 2. Prior and posterior densities - shocks
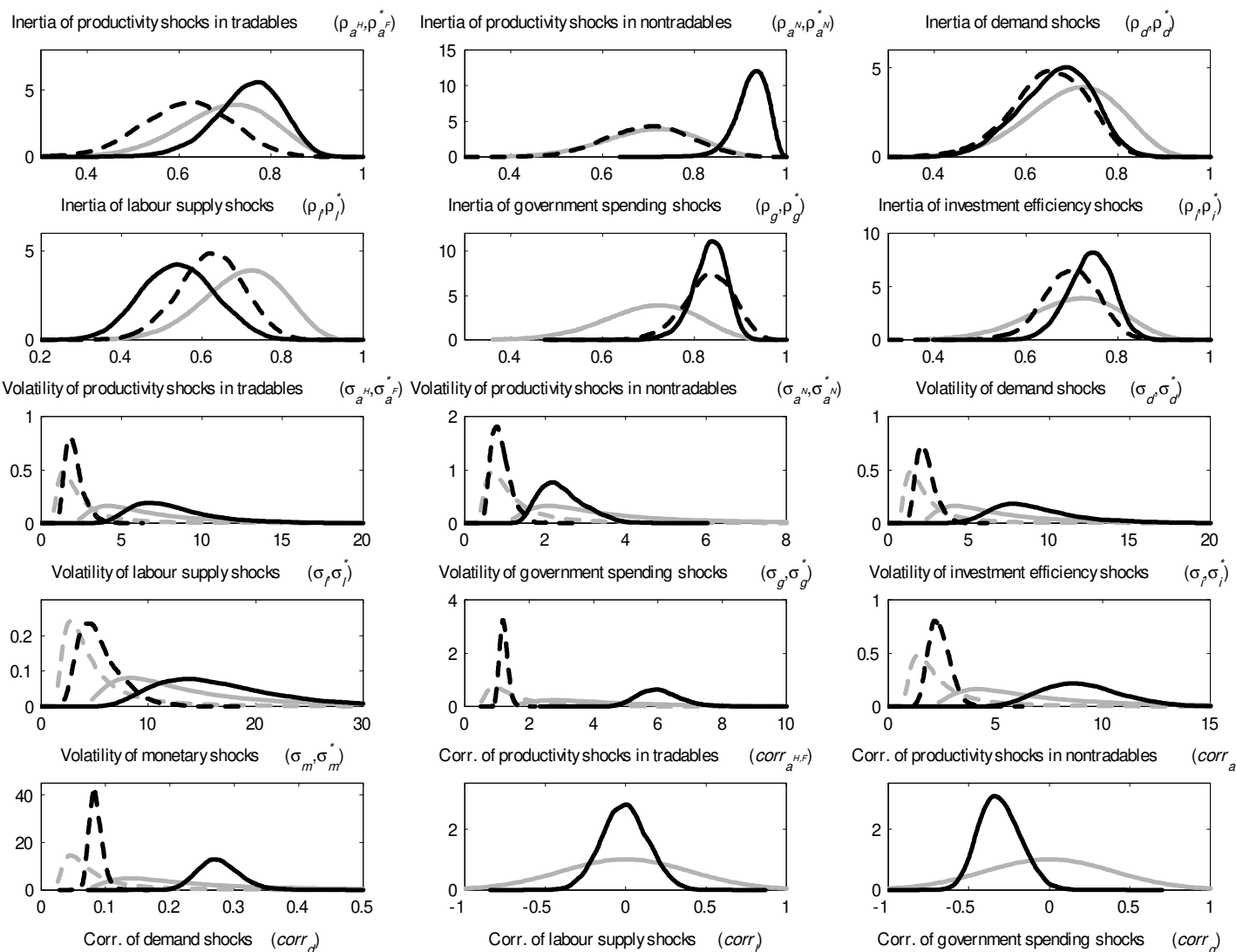

Corr. of productivity shocks in nontradables $\quad\left(\operatorname{corr}_{a^{N}}\right)$
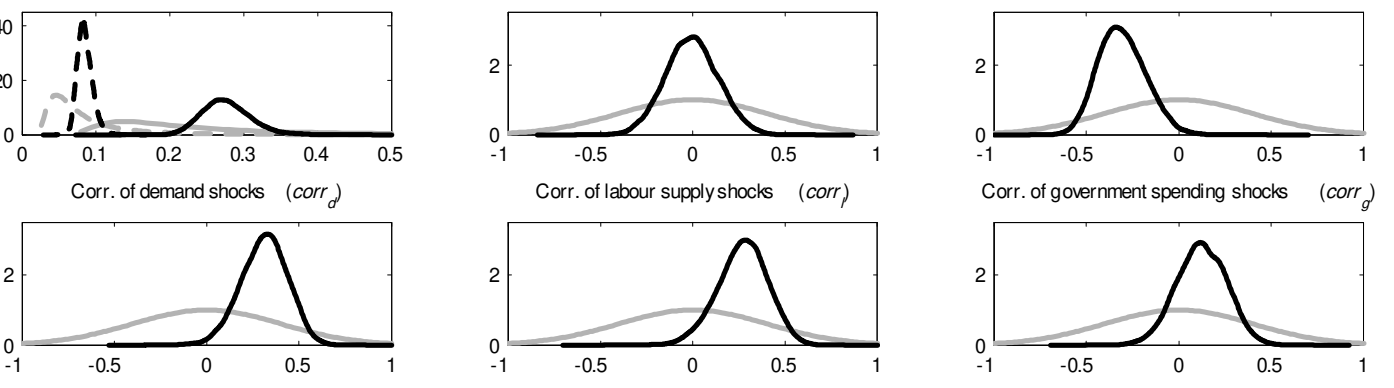

Corr. of investment efficiency shocks (corr)
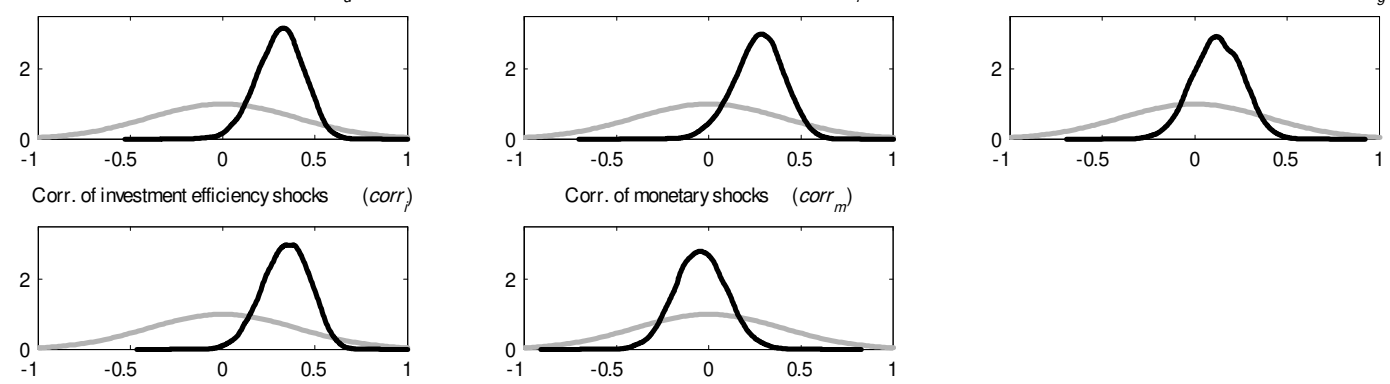

Note: grey solid line - prior for Poland, grey dashed line - prior for the euro area, black solid line posterior for Poland, dashed solid line - posterior for the euro area. 
Figure 3. Impulse response: tradable goods productivity shock in Poland
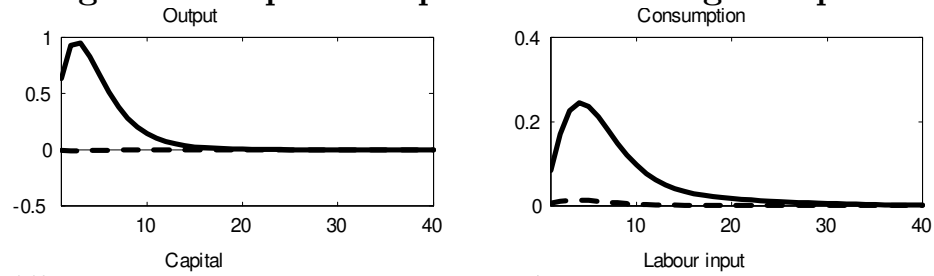

Investment
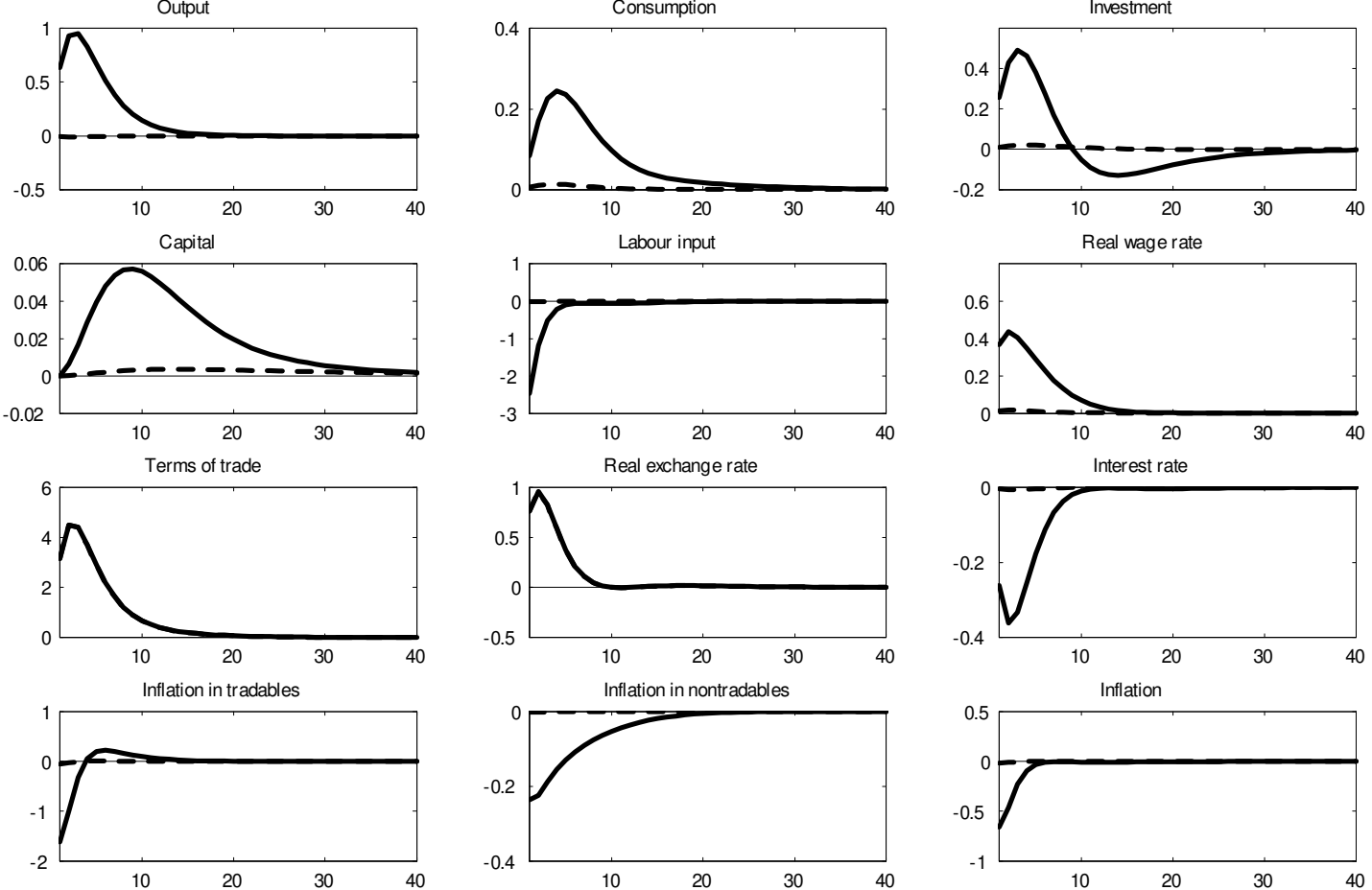

Note: solid line - Poland, dashed line - euro area.

Figure 4. Impulse response: tradable goods productivity shock in the euro area

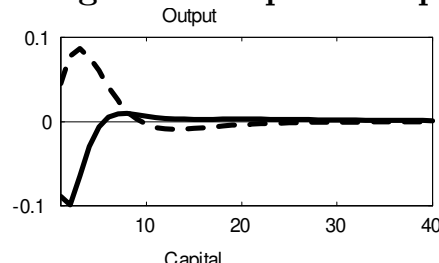
Consumption
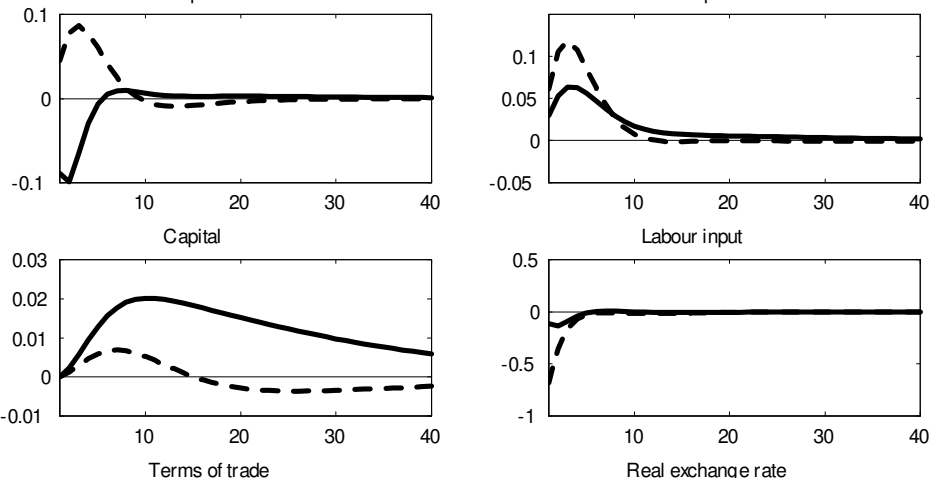

Investment
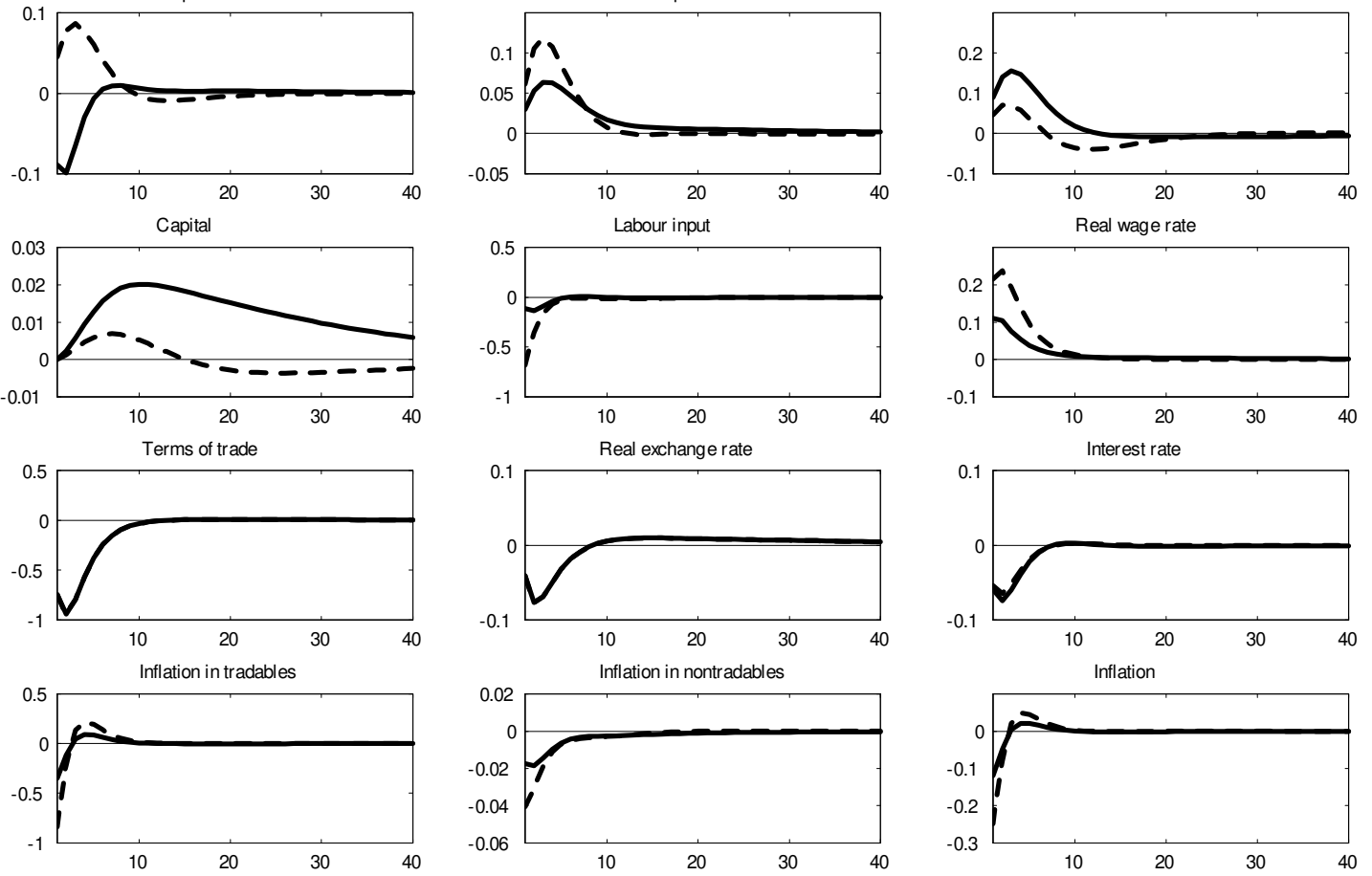

Note: solid line - Poland, dashed line - euro area. 
Figure 5. Impulse response: nontradable goods productivity shock in Poland
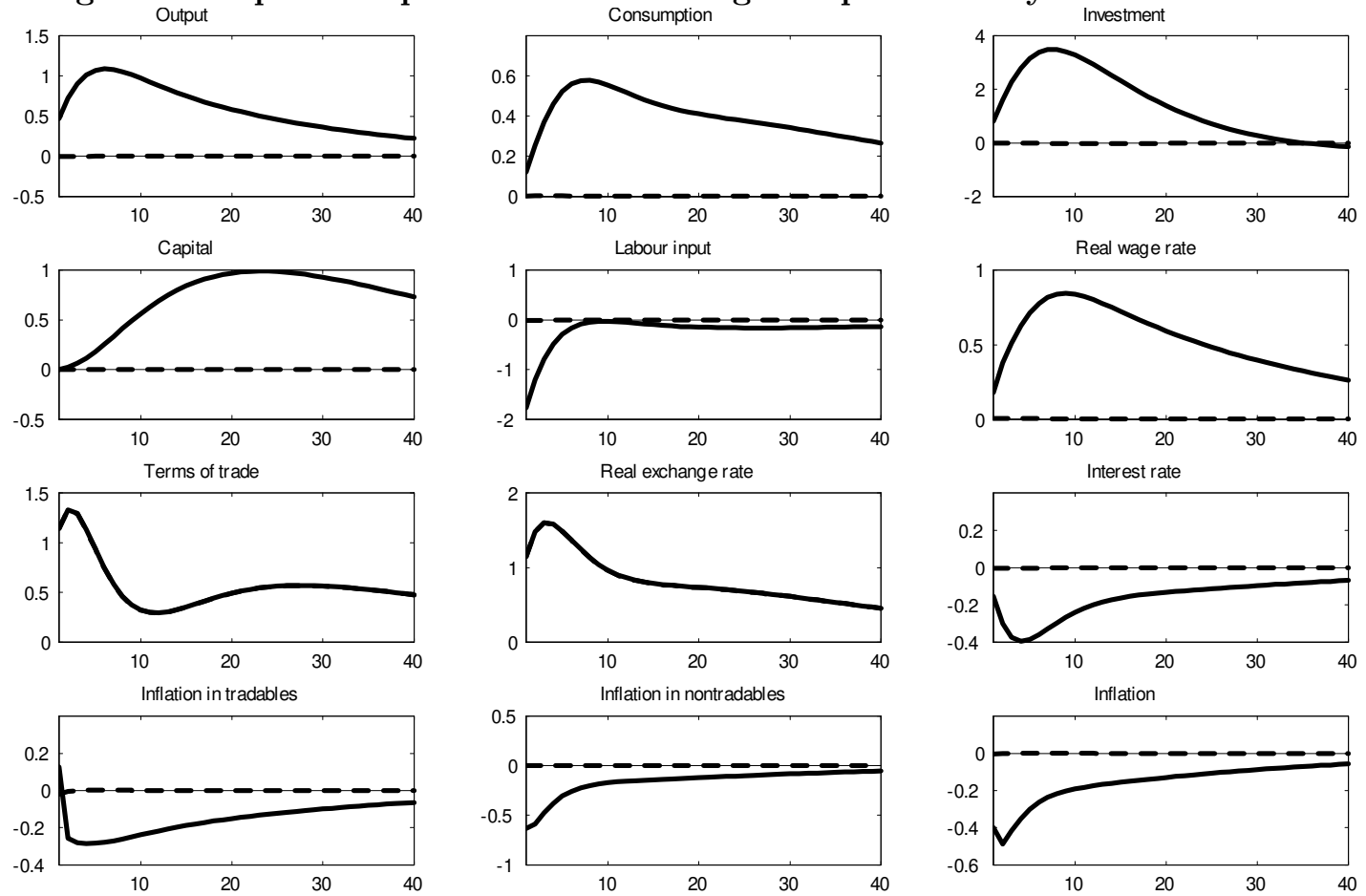

Note: solid line - Poland, dashed line - euro area.

Figure 6. Impulse response: nontradable goods productivity shock in the euro area
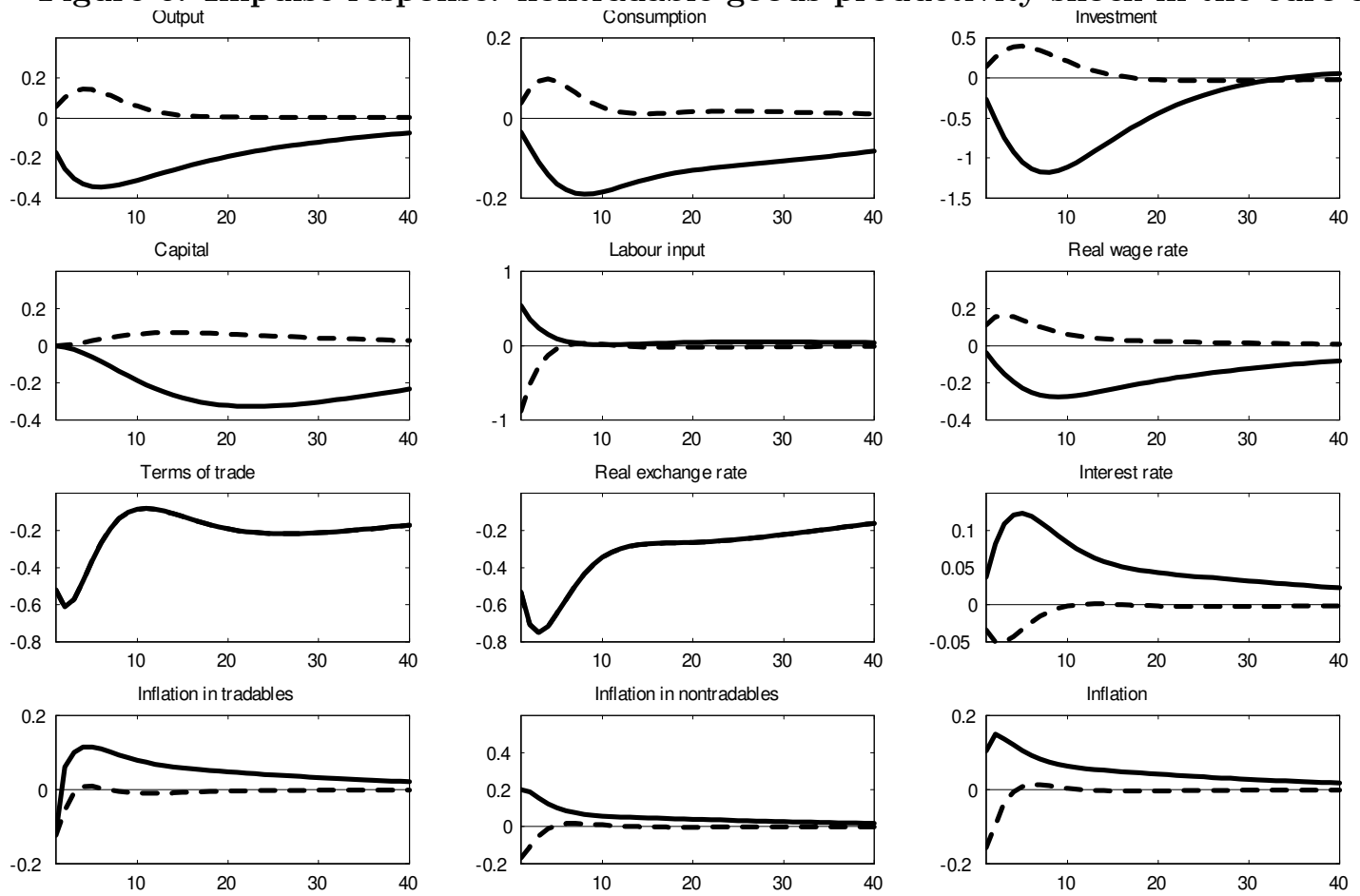

Note: solid line - Poland, dashed line - euro area. 
Figure 7. Impulse response: consumption preference shock in Poland
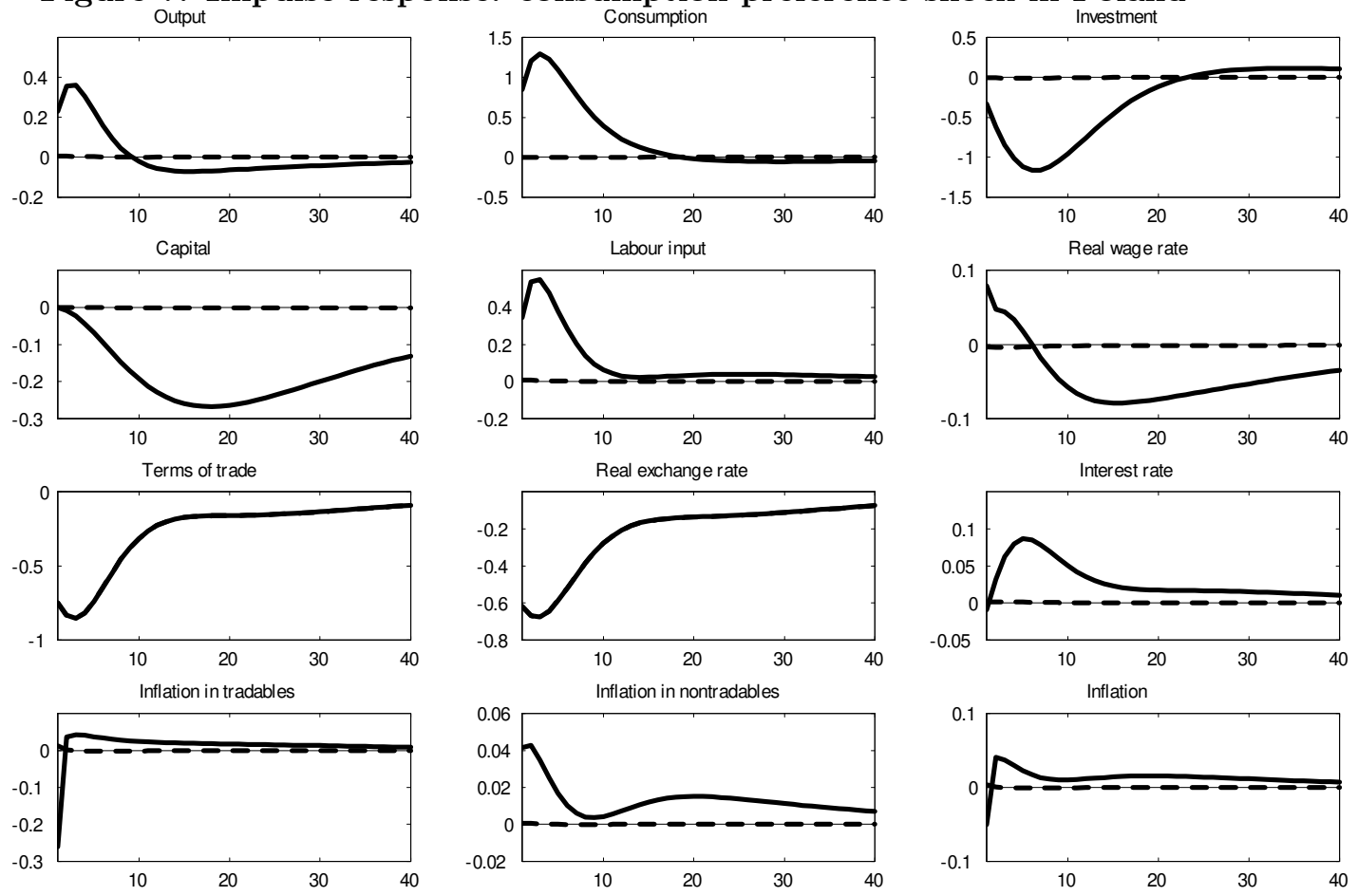

Note: solid line - Poland, dashed line - euro area.

Figure 8. Impulse response: consumption preference shock in the euro area
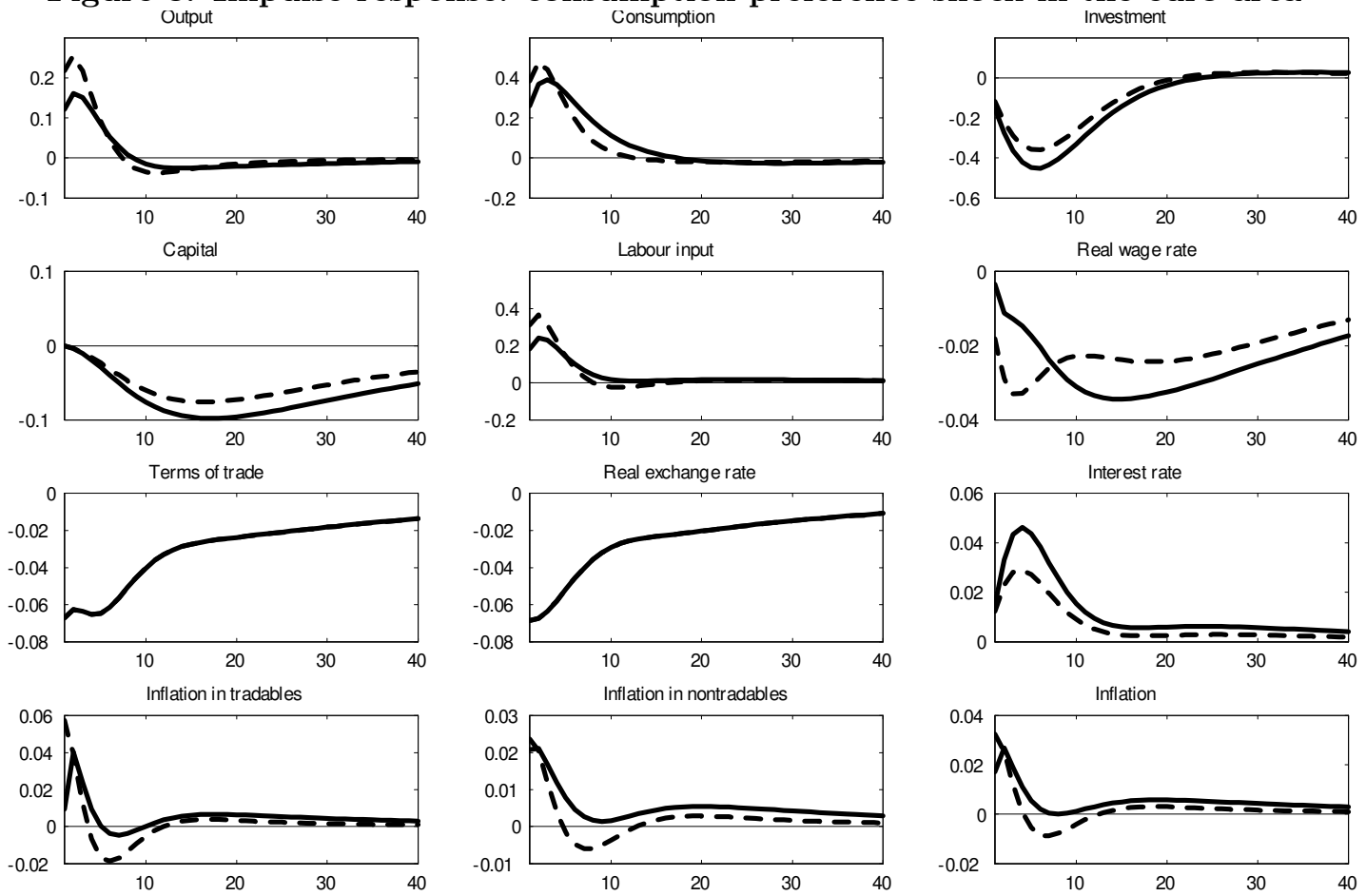

Note: solid line - Poland, dashed line - euro area. 
Figure 9. Impulse response: labour supply shock in Poland
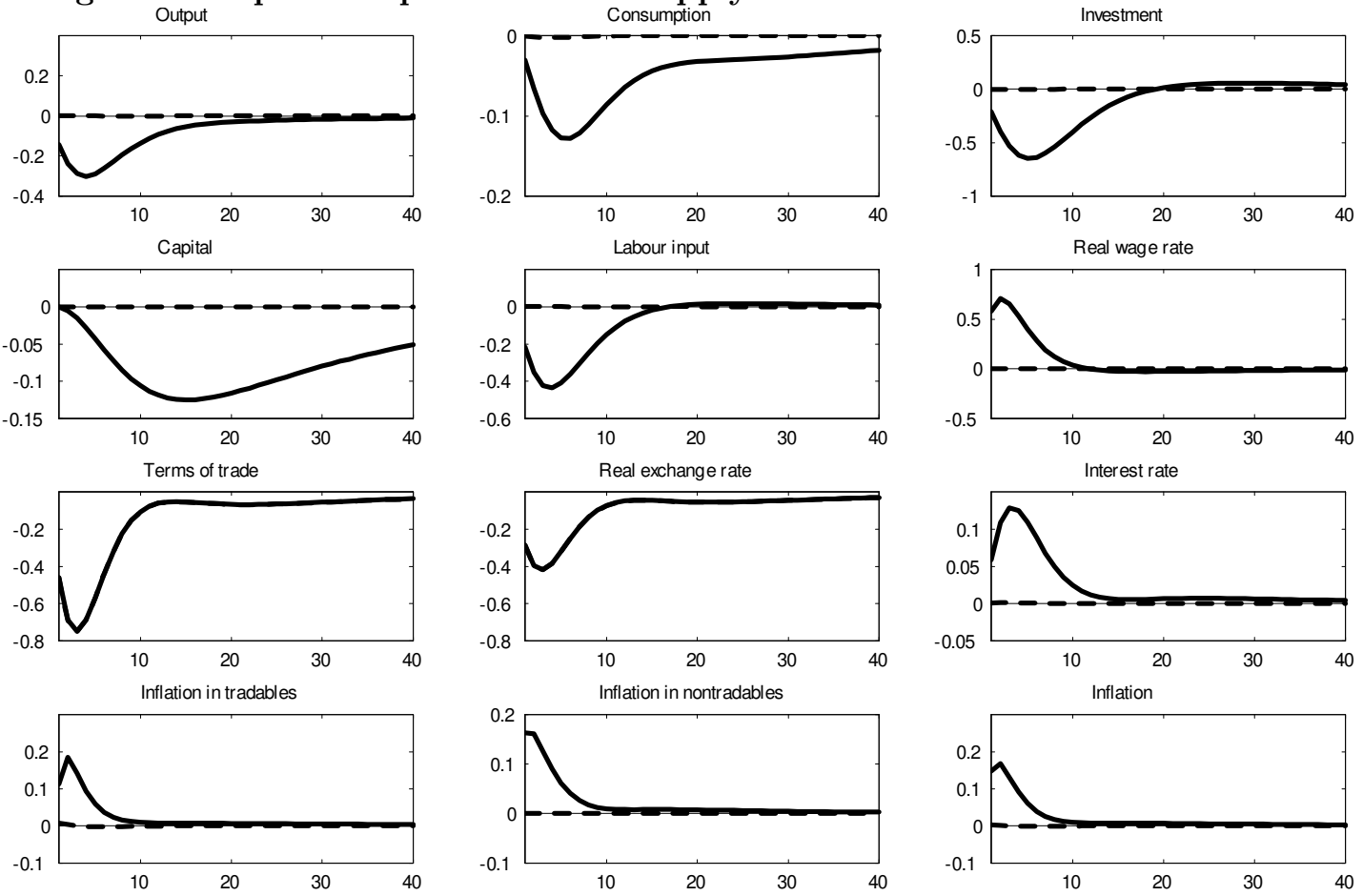

Note: solid line - Poland, dashed line - euro area.

Figure 10. Impulse response: labour supply shock in the euro area
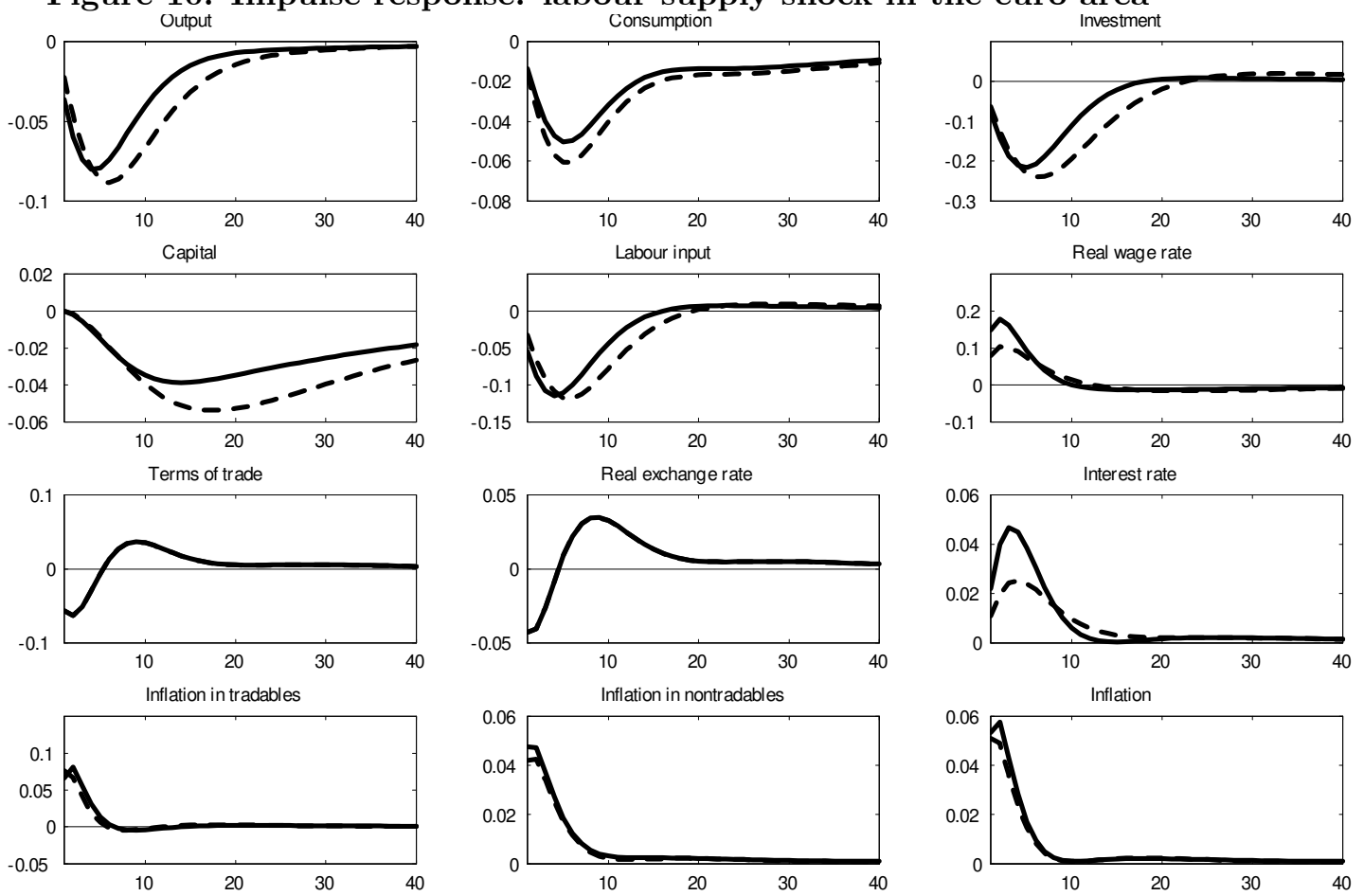

Note: solid line - Poland, dashed line - euro area. 
Figure 11. Impulse response: government spending shock in Poland
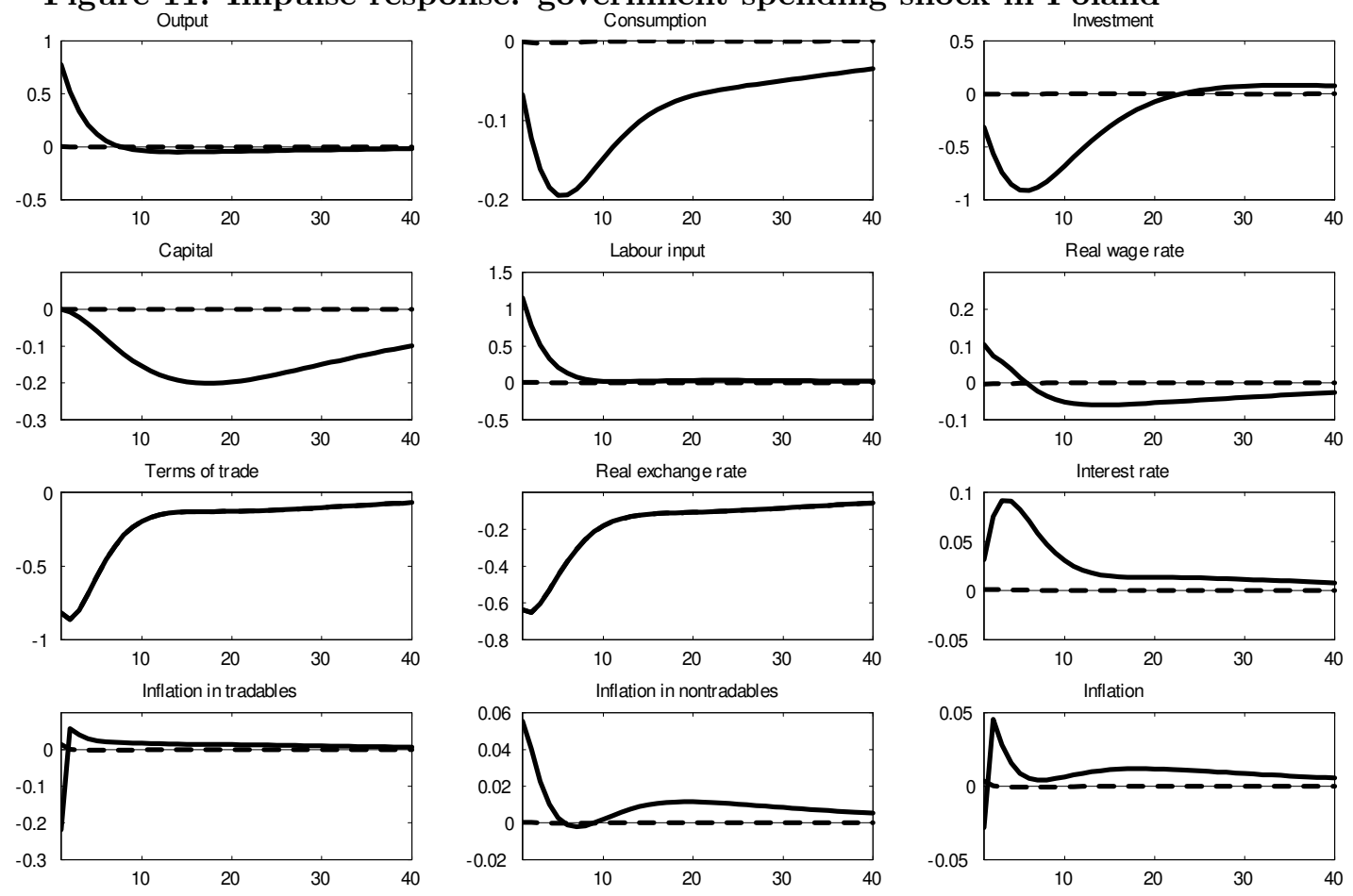

Note: solid line - Poland, dashed line - euro area.

Figure 12. Impulse response: government spending shock in the euro area
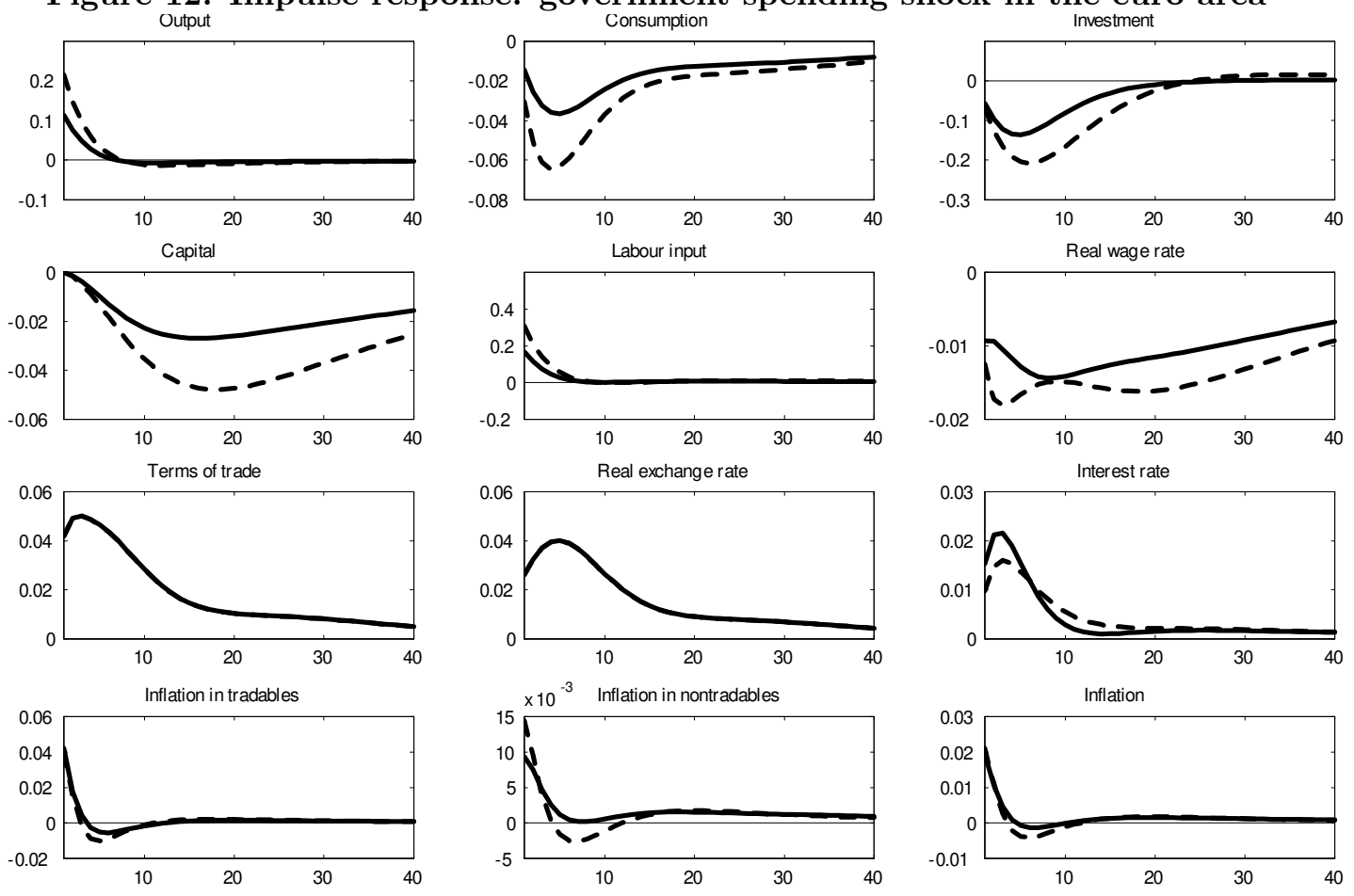

Note: solid line - Poland, dashed line - euro area. 
Figure 13. Impulse response: investment efficiency shock in Poland
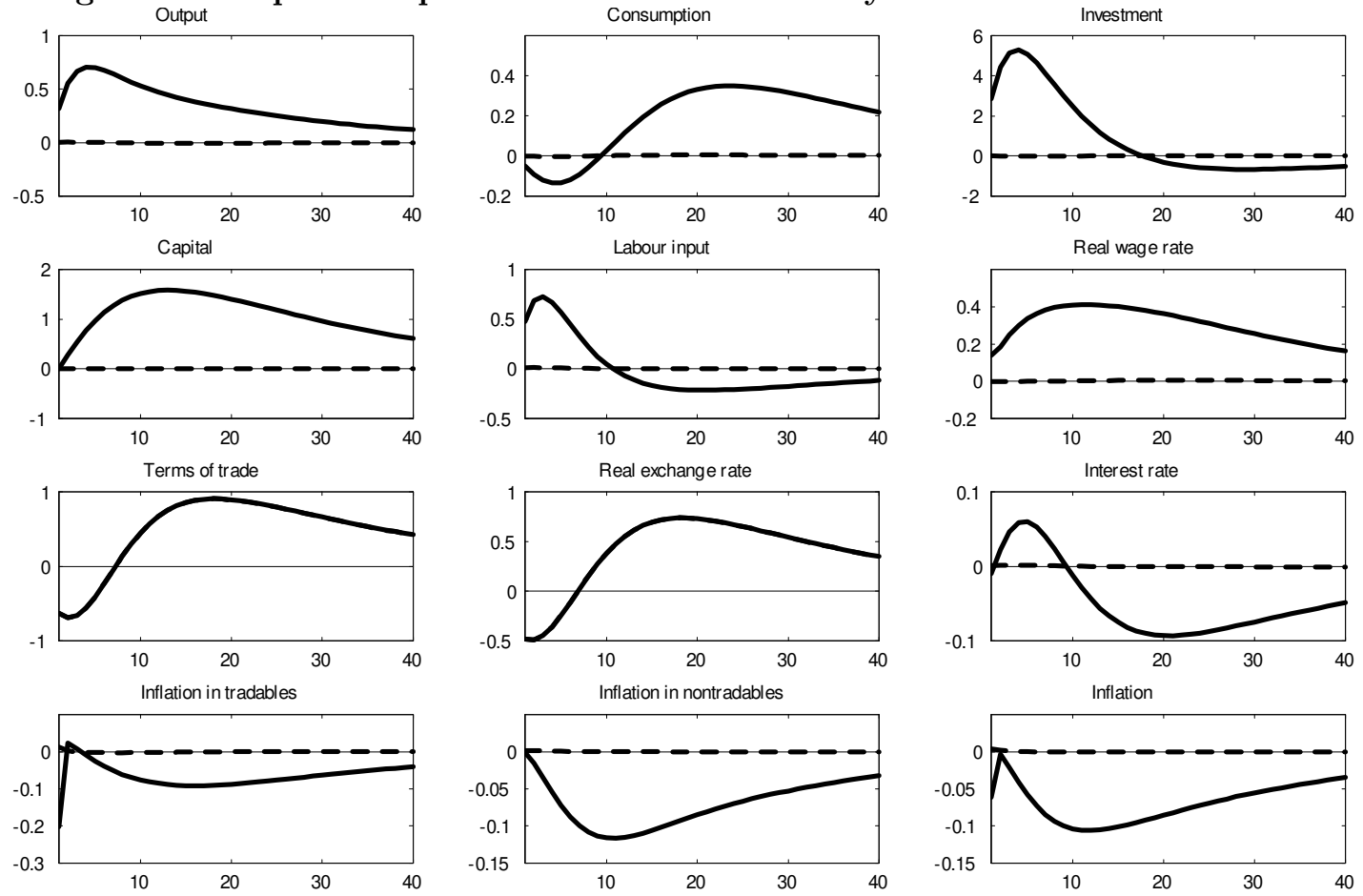

Note: solid line - Poland, dashed line - euro area.

Figure 14. Impulse response: investment efficiency shock in the euro area
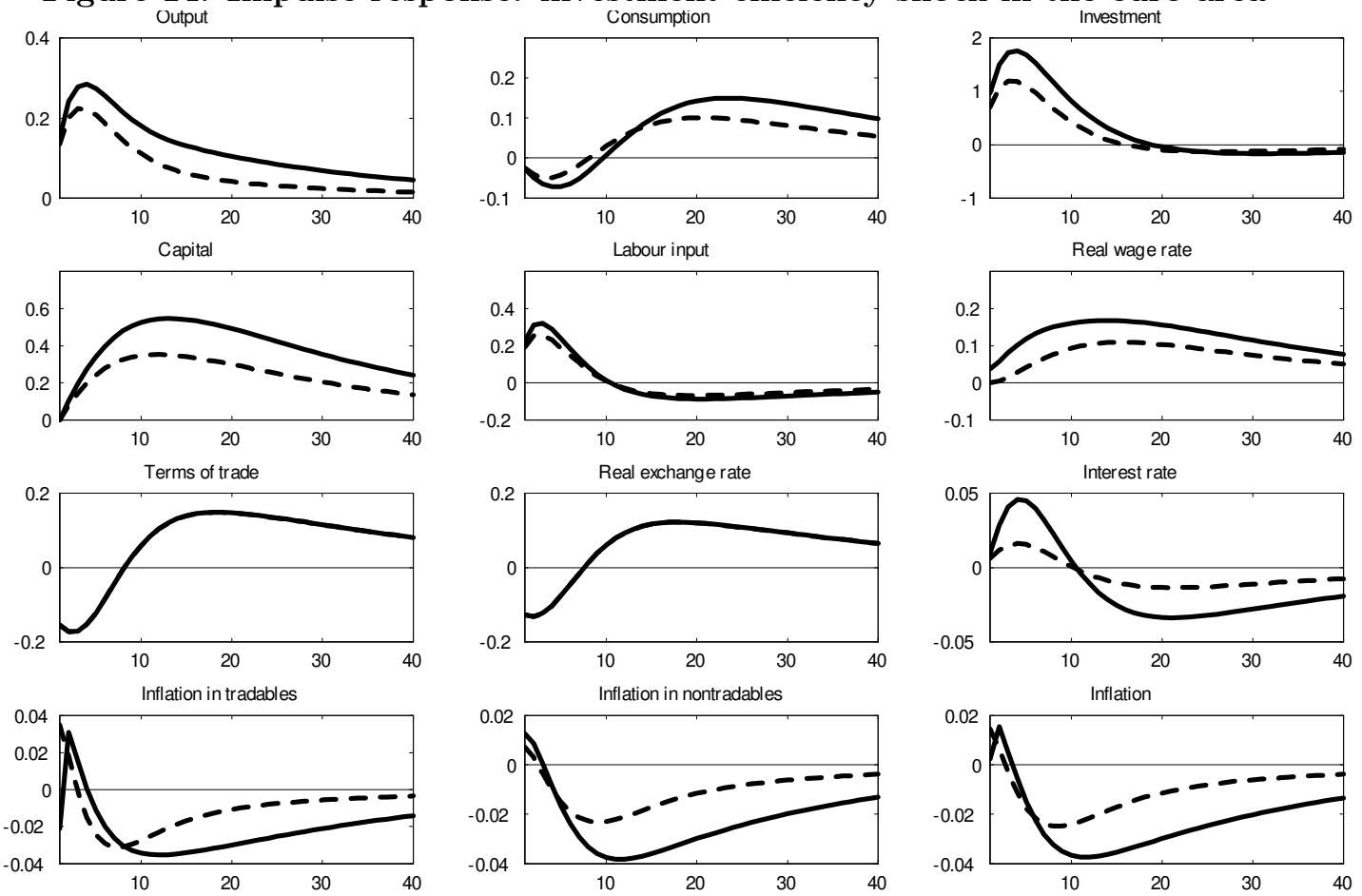

Note: solid line - Poland, dashed line - euro area. 
Figure 15. Impulse response: monetary policy shock in Poland
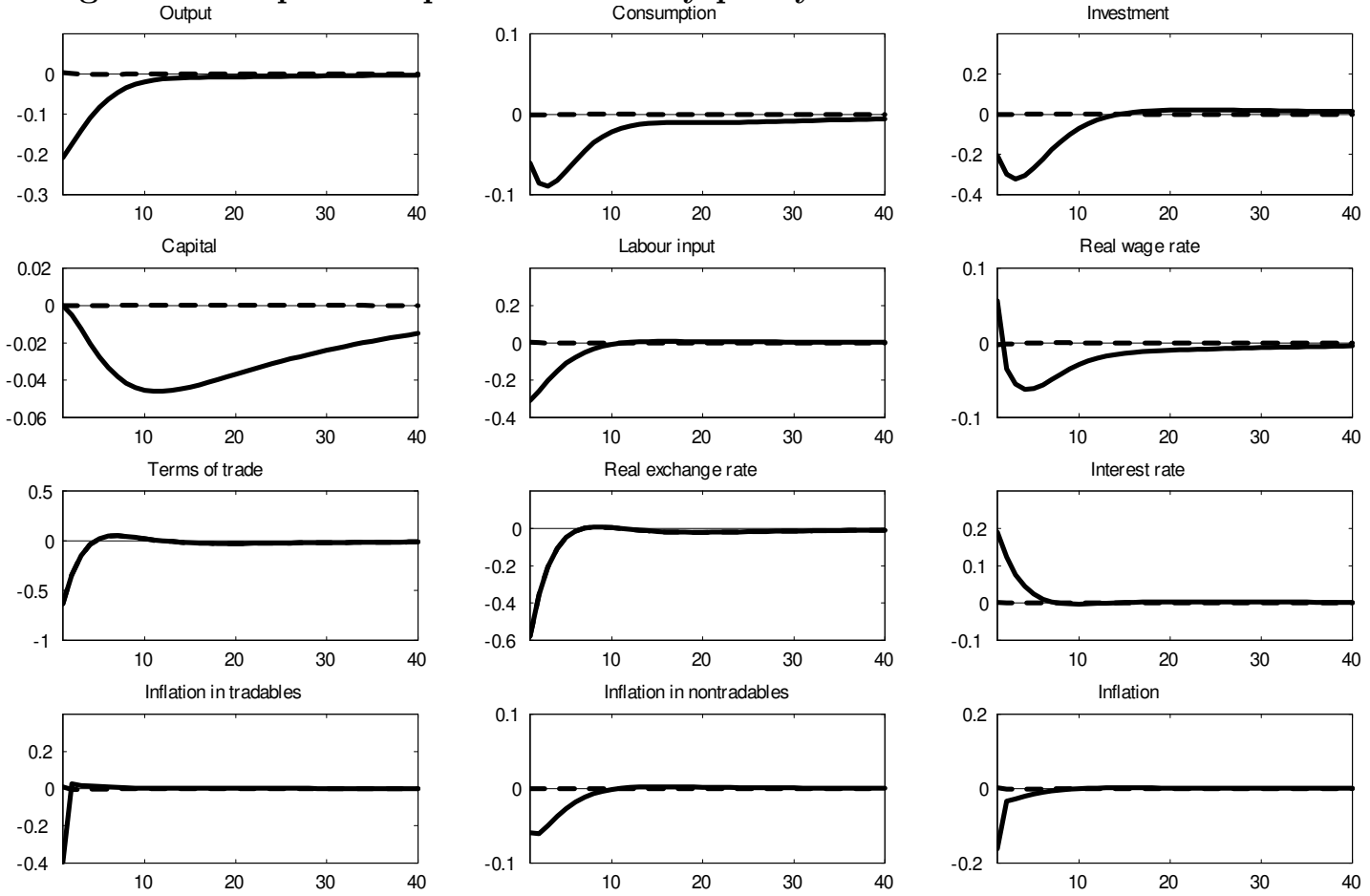

Note: solid line - Poland, dashed line - euro area.

Figure 16. Impulse response: monetary policy shock in the euro area
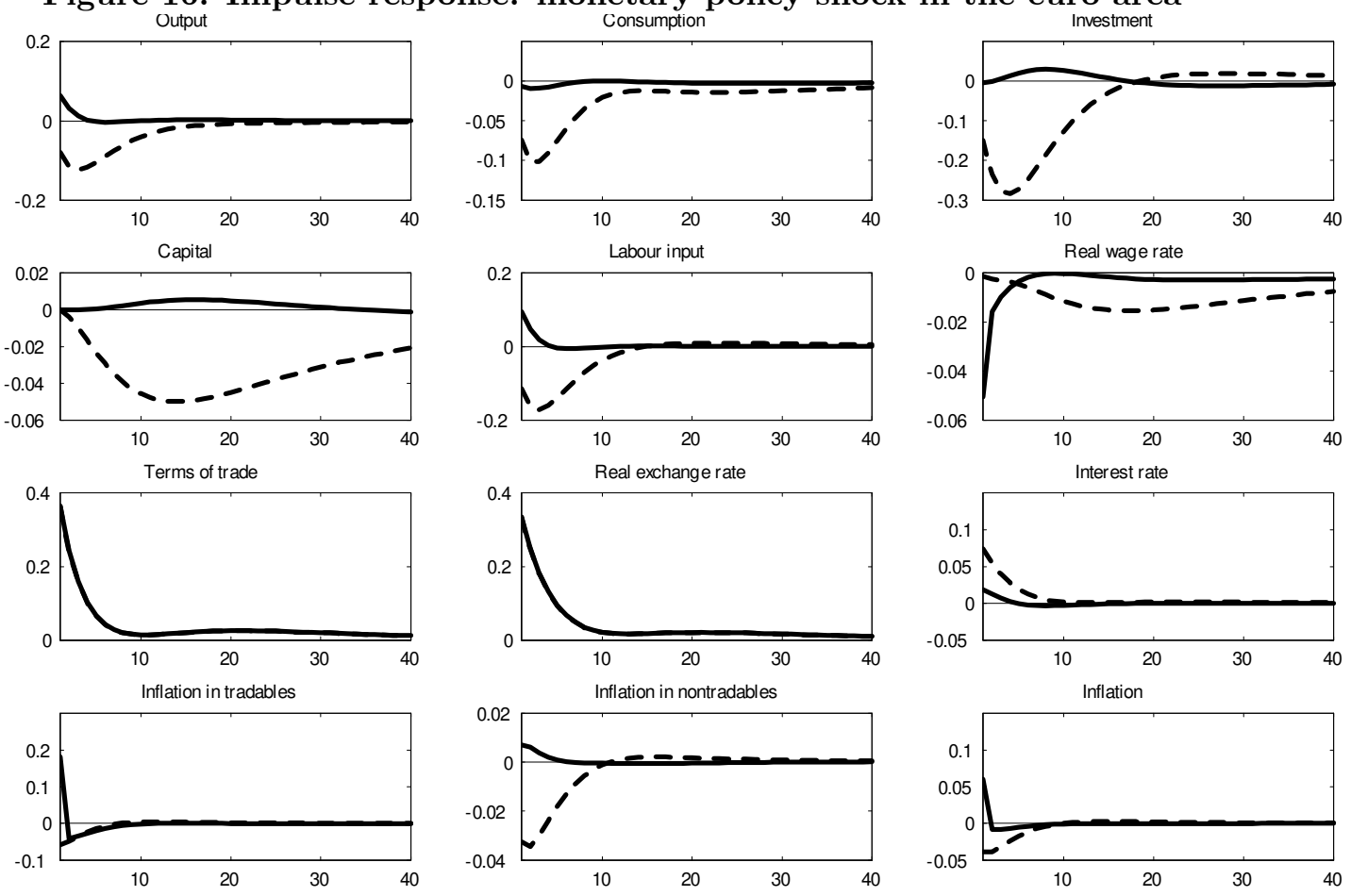

Note: solid line - Poland, dashed line - euro area. 
Figure 17. Stochastic disturbances
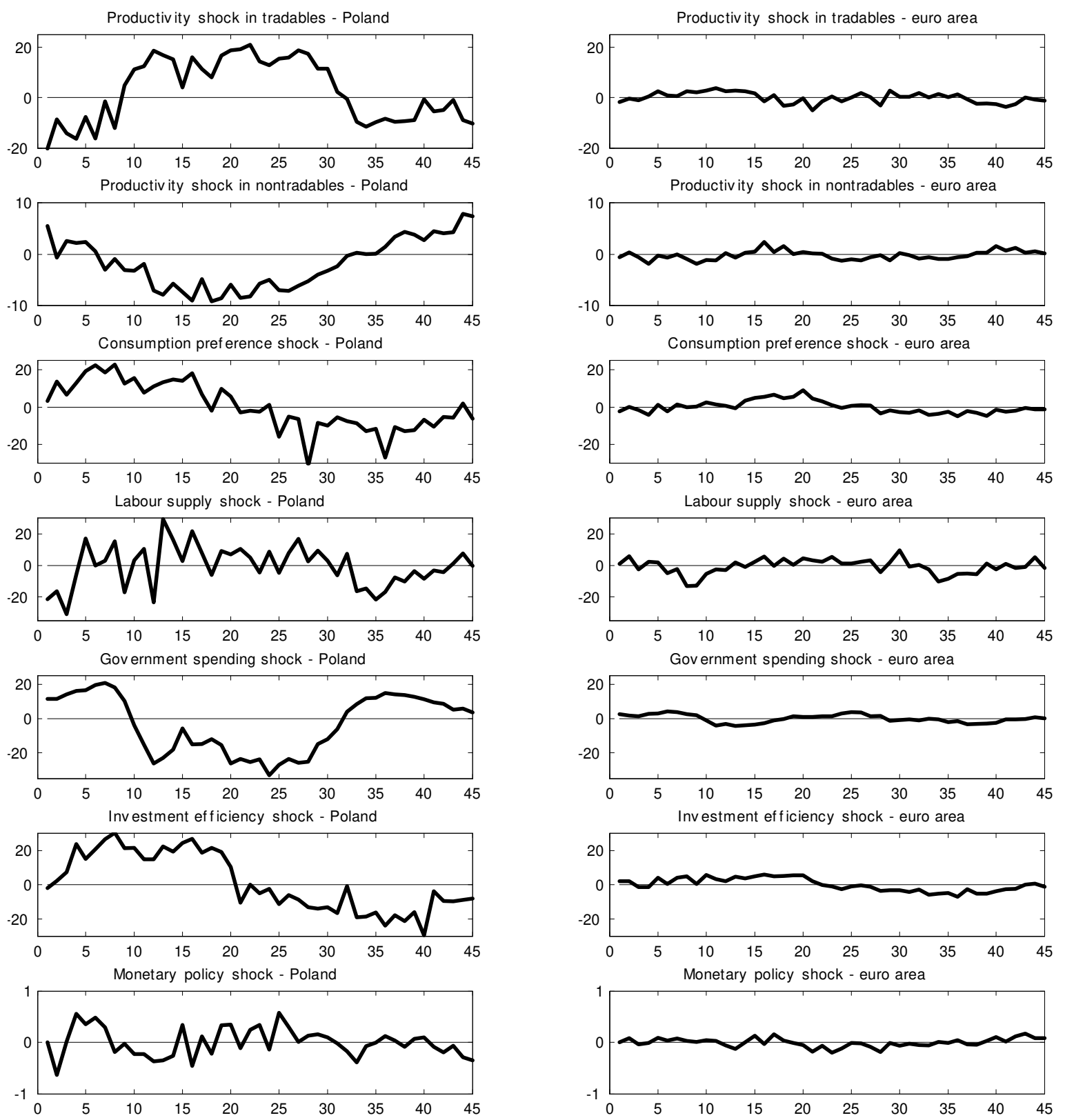
Figure 18. Data and one-step-ahead forecasts
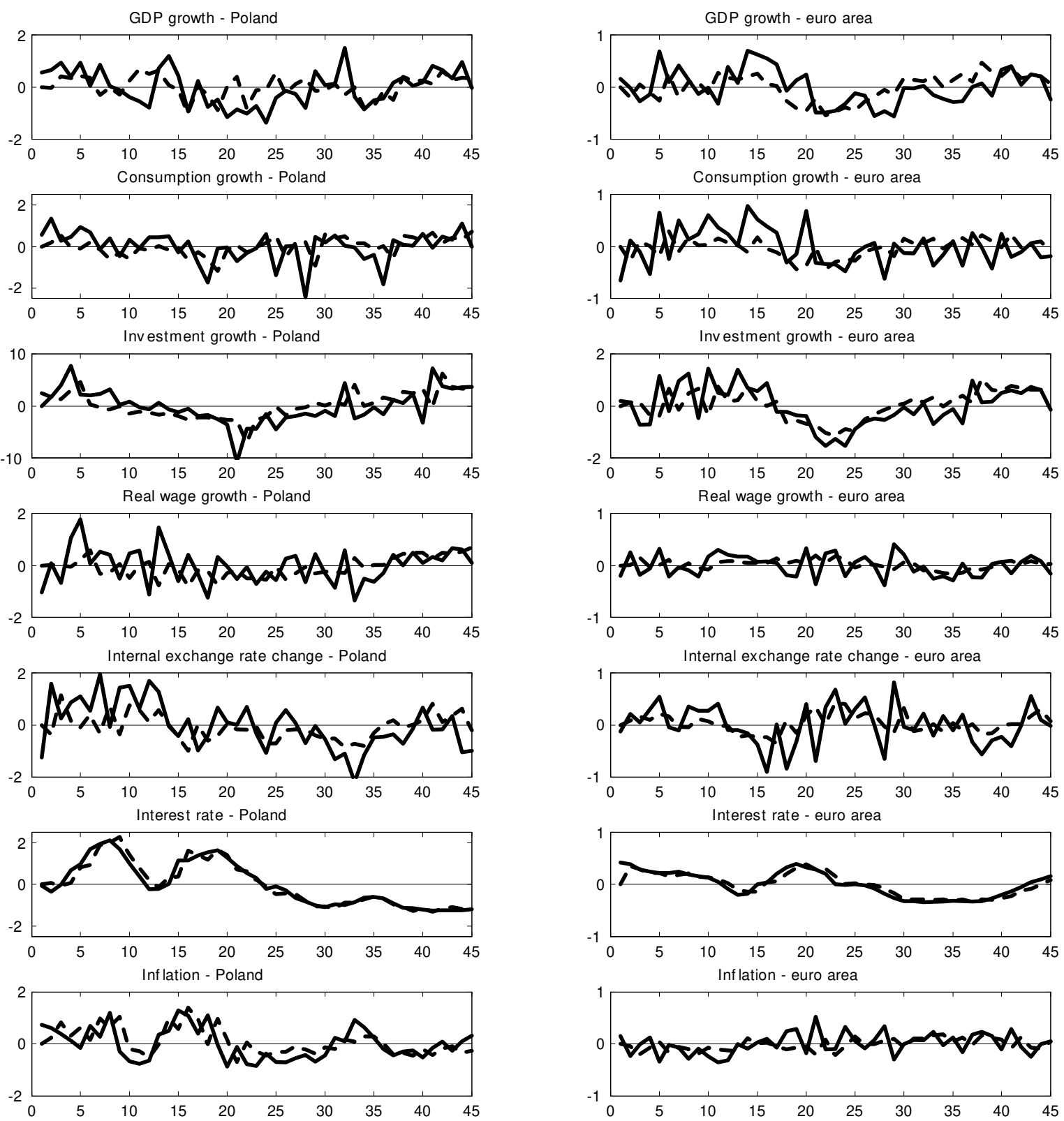

Note: solid line - Poland, dashed line - euro area. 


\section{Appendix. Log-linearized model equations}

This appendix lists all log-linearized equations of the model. Variables in small letters denote their $\log$ deviations from the deterministic steady state.

Market clearing conditions ${ }^{25}$

$$
\begin{aligned}
& y_{H, t}=\frac{\bar{C}}{\bar{Y}_{H}} \frac{\gamma_{c} \alpha}{1+\omega}\left(c_{t}+\left(1-\gamma_{c}\right) x_{t}+(1-\alpha) s_{t}\right)+\frac{\bar{C}^{*}}{\bar{Y}_{H}} \frac{1-n}{n} \frac{\gamma_{c}^{*} \alpha^{*}}{1+\omega^{*}}\left(c_{t}^{*}+\left(1-\gamma_{c}^{*}\right) x_{t}^{*}+\left(1-\alpha^{*}\right) s_{t}\right)+ \\
& +\frac{\bar{I}}{\bar{Y}_{H}} \gamma_{i} \alpha\left(i_{t}+\left(1-\gamma_{i}\right)(1+\omega) x_{t}+(1-\alpha) s_{t}\right)+\frac{\bar{I}^{*}}{\bar{Y}_{H}} \frac{1-n}{n} \gamma_{i}^{*} \alpha^{*}\left(i_{t}^{*}+\left(1-\gamma_{i}^{*}\right)\left(1+\omega^{*}\right) x_{t}^{*}+\left(1-\alpha^{*}\right) s_{t}\right) \\
& y_{F, t}^{*}=\frac{\bar{C}^{*}}{\bar{Y}_{F}^{*}} \frac{\gamma_{c}^{*}\left(1-\alpha^{*}\right)}{1+\omega^{*}}\left(c_{t}^{*}+\left(1-\gamma_{c}^{*}\right) x_{t}^{*}+\alpha^{*} s_{t}\right)+\frac{\bar{C}}{\bar{Y}_{F}^{*}} \frac{1-n}{n} \frac{\gamma_{c}(1-\alpha)}{1+\omega}\left(c_{t}+\left(1-\gamma_{c}\right) x_{t}-\alpha s_{t}\right)+ \\
& +\frac{\bar{I}^{*}}{\bar{Y}_{F}^{*}} \gamma_{i}^{*}\left(1-\alpha^{*}\right)\left(i_{t}^{*}+\left(1-\gamma_{i}^{*}\right)\left(1+\omega^{*}\right) x_{t}^{*}+\alpha^{*} s_{t}\right)+\frac{\bar{I}}{\bar{Y}_{F}^{*}} \frac{1-n}{n} \gamma_{i}(1-\alpha)\left(i_{t}+\left(1-\gamma_{i}\right)(1+\omega) x_{t}-\alpha s_{t}\right) \\
& y_{N, t}=\frac{\bar{C}}{\bar{Y}_{N}}\left[\left(1-\gamma_{c}\right)\left(c_{t}-\gamma_{c} x_{t}\right)+\frac{\gamma_{c} \omega}{1+\omega}\left(c_{t}+\left(1-\gamma_{c}\right) x_{t}\right)\right]+ \\
& +\frac{\bar{I}}{\bar{Y}_{N}}\left(1-\gamma_{i}\right)\left(i_{t}-\gamma_{i} x_{t}\right)+\frac{\bar{G}}{\bar{Y}_{N}} \varepsilon_{g, t} \\
& y_{N, t}^{*}=\frac{\bar{C}^{*}}{\bar{Y}_{N}^{*}}\left[\left(1-\gamma_{c}^{*}\right)\left(c_{t}^{*}-\gamma_{c}^{*} x_{t}^{*}\right)+\frac{\gamma_{c}^{*} \omega^{*}}{1+\omega^{*}}\left(c_{t}^{*}+\left(1-\gamma_{c}^{*}\right) x_{t}^{*}\right)\right]+ \\
& +\frac{\bar{I}^{*}}{\bar{Y}_{N}^{*}}\left(1-\gamma_{i}^{*}\right)\left(i_{t}^{*}-\gamma_{i}^{*} x_{t}^{*}\right)+\frac{\bar{G}^{*}}{\bar{Y}_{N}^{*}} \varepsilon_{g, t}^{*} \\
& y_{t}=\frac{\bar{Y}_{H}}{\bar{Y}} y_{H, t}+\frac{\bar{Y}_{N}}{\bar{Y}} y_{N, t} \\
& y_{t}^{*}=\frac{\bar{Y}_{F}^{*}}{\bar{Y}^{*}} y_{F, t}^{*}+\frac{\bar{Y}_{N}^{*}}{\bar{Y}^{*}} y_{N, t}^{*}
\end{aligned}
$$

Consumption (Euler) equations

$$
\begin{gathered}
c_{t}-h c_{t-1}=E_{t}\left(c_{t+1}-h c_{t}\right)-\frac{1-h}{\sigma}\left(r_{t}-E_{t} \pi_{t+1}\right)+\frac{1}{\sigma}\left(\varepsilon_{d, t}-\varepsilon_{d, t+1}\right) \\
c_{t}^{*}-h^{*} c_{t-1}^{*}=E_{t}\left(c_{t+1}^{*}-h^{*} c_{t}^{*}\right)-\frac{1-h^{*}}{\sigma^{*}}\left(r_{t}-E_{t} \pi_{t+1}^{*}\right)+\frac{1}{\sigma^{*}}\left(\varepsilon_{d, t}^{*}-\varepsilon_{d, t+1}^{*}\right)
\end{gathered}
$$

International risk sharing condition

$$
q_{t}=\varepsilon_{d, t}^{*}-\varepsilon_{d, t}-\frac{\sigma^{*}}{1-h^{*}}\left(c_{t}^{*}-h^{*} c_{t-1}^{*}\right)+\frac{\sigma}{1-h}\left(c_{t}-h c_{t-1}\right)
$$

Capital accumulation

$$
k_{t+1}=(1-\tau) k_{t}+\tau\left(i_{t}+\varepsilon_{i, t}\right)
$$

\footnotetext{
${ }^{25}$ Steady-state ratios are expressed in nominal terms. For $\frac{\bar{C}^{*}}{\bar{Y}_{H}}, \frac{\bar{I}^{*}}{\bar{Y}_{H}}, \frac{\bar{C}}{\bar{Y}_{F}^{*}}$ and $\frac{\bar{I}}{\bar{Y}_{F}^{*}}$ we use normalization $\bar{Y}=\bar{Y}^{*}$.
} 


$$
k_{t+1}^{*}=\left(1-\tau^{*}\right) k_{t}^{*}+\tau^{*}\left(i_{t}^{*}+\varepsilon_{i, t}^{*}\right)
$$

Real cost of capital

$$
\begin{gathered}
r_{t}^{k}=w_{t}+l_{t}+k_{t} \\
r_{t}^{k *}=w_{t}^{*}+l_{t}^{*}+k_{t}^{*}
\end{gathered}
$$

Investment demand

$$
\begin{gathered}
i_{t}-i_{t-1}=\beta\left(i_{t+1}-i_{t}\right)+\frac{1}{S^{\prime \prime}}\left(q_{T, t}+\varepsilon_{i, t}\right)-\frac{\gamma_{i}(1+\omega)+\gamma_{c}}{S^{\prime \prime}} x_{t} \\
i_{t}^{*}-i_{t-1}^{*}=\beta^{*}\left(i_{t+1}^{*}-i_{t}^{*}\right)+\frac{1}{S^{\prime \prime *}}\left(q_{T, t}^{*}+\varepsilon_{i, t}^{*}\right)-\frac{\gamma_{i}^{*}\left(1+\omega^{*}\right)+\gamma_{c}^{*}}{S^{\prime \prime^{*}}} x_{t}^{*}
\end{gathered}
$$

Price of installed capital

$$
\begin{gathered}
q_{T, t}=\beta(1-\tau) q_{T, t+1}-\left(r_{t}-E_{t} \pi_{t+1}\right)+(1-\beta(1-\tau)) r_{t+1}^{k} \\
q_{T, t}^{*}=\beta^{*}\left(1-\tau^{*}\right) q_{T, t+1}^{*}-\left(r_{t}^{*}-E_{t} \pi_{t+1}^{*}\right)+\left(1-\beta^{*}\left(1-\tau^{*}\right)\right) r_{t+1}^{k *}
\end{gathered}
$$

Labour input

$$
\begin{gathered}
l_{t}=\eta\left(z_{t}-w_{t}\right)+\frac{\bar{Y}_{H}}{\bar{Y}}\left(y_{H, t}-\varepsilon_{a^{H}, t}\right)+\frac{\bar{Y}_{N}}{\bar{Y}}\left(y_{N, t}-\varepsilon_{a^{N}, t}\right) \\
l_{t}^{*}=\eta^{*}\left(z_{t}^{*}-w_{t}^{*}\right)+\frac{\bar{Y}_{F}^{*}}{\bar{Y}^{*}}\left(y_{F, t}^{*}-\varepsilon_{a^{F}, t}^{*}\right)+\frac{\bar{Y}_{N}^{*}}{\bar{Y}^{*}}\left(y_{N, t}^{*}-\varepsilon_{a^{N}, t}^{*}\right)
\end{gathered}
$$

Real wage rate

$$
\begin{gathered}
\Delta w_{t}=\frac{\left(1-\theta_{W}\right)\left(1-\beta \theta_{W}\right)}{\theta_{W}(1+\phi \varphi)}\left(m r s_{t}-w_{t}\right)+\beta E_{t} \Delta w_{t+1}+\beta E_{t}\left(\pi_{t+1}-\delta_{W} \pi_{t}\right)-\left(\pi_{t}-\delta_{W} \pi_{t-1}\right) \\
\Delta w_{t}^{*}=\frac{\left(1-\theta_{W}^{*}\right)\left(1-\beta^{*} \theta_{W}^{*}\right)}{\theta_{W}^{*}\left(1+\phi^{*} \varphi^{*}\right)}\left(m r s_{t}^{*}-w_{t}^{*}\right)+\beta^{*} E_{t} \Delta w_{t+1}^{*}+\beta^{*} E_{t}\left(\pi_{t+1}^{*}-\delta_{W}^{*} \pi_{t}^{*}\right)-\left(\pi_{t}^{*}-\delta_{W}^{*} \pi_{t-1}^{*}\right)
\end{gathered}
$$

Marginal rate of substitution between consumption and labour

$$
\begin{gathered}
m r s_{t}=\varepsilon_{l, t}+\varphi l_{t}-\varepsilon_{d, t}+\frac{\sigma}{1-h}\left(c_{t}-h c_{t-1}\right) \\
m r s_{t}^{*}=\varepsilon_{l, t}^{*}+\varphi^{*} l_{t}^{*}-\varepsilon_{d, t}^{*}+\frac{\sigma^{*}}{1-h^{*}}\left(c_{t}^{*}-h^{*} c_{t-1}^{*}\right)
\end{gathered}
$$

Home tradable goods Phillips curves

$$
\pi_{H, t}-\delta_{H} \pi_{H, t-1}=\frac{\left(1-\theta_{H}\right)\left(1-\beta \theta_{H}\right)}{\theta_{H}} m c_{H, t}+\beta E_{t}\left(\pi_{H, t+1}-\delta_{H} \pi_{H, t}\right)
$$




$$
\pi_{F, t}^{*}-\delta_{F}^{*} \pi_{F, t-1}^{*}=\frac{\left(1-\theta_{F}^{*}\right)\left(1-\beta^{*} \theta_{F}^{*}\right)}{\theta_{F}^{*}} m c_{F, t}^{*}+\beta^{*} E_{t}\left(\pi_{F, t+1}^{*}-\delta_{F}^{*} \pi_{F, t}^{*}\right)
$$

Nontradable goods Phillips curves

$$
\begin{gathered}
\pi_{N, t}-\delta_{N} \pi_{N, t-1}=\frac{\left(1-\theta_{N}\right)\left(1-\beta \theta_{N}\right)}{\theta_{N}} m c_{N, t}+\beta E_{t}\left(\pi_{N, t+1}-\delta_{N} \pi_{N, t}\right) \\
\pi_{N, t}^{*}-\delta_{N}^{*} \pi_{N, t-1}^{*}=\frac{\left(1-\theta_{N}^{*}\right)\left(1-\beta^{*} \theta_{N}^{*}\right)}{\theta_{N}^{*}} m c_{N, t}^{*}+\beta^{*} E_{t}\left(\pi_{N, t+1}^{*}-\delta_{N}^{*} \pi_{N, t}^{*}\right)
\end{gathered}
$$

Real marginal cost for tradable goods

$$
\begin{aligned}
& m c_{H, t}=(1-\eta) w_{t}+\eta r_{t}^{k}-\varepsilon_{a^{H}, t}+(1-\alpha) s_{t}+(1+\omega-\gamma) x_{t} \\
& m c_{F, t}^{*}=\left(1-\eta^{*}\right) w_{t}^{*}+\eta^{*} r_{t}^{k *}-\varepsilon_{a^{F}, t}^{*}-\alpha^{*} s_{t}+\left(1+\omega^{*}-\gamma^{*}\right) x_{t}^{*}
\end{aligned}
$$

Real marginal cost for nontradable goods

$$
\begin{gathered}
m c_{N, t}=(1-\eta) w_{t}+\eta r_{t}^{k}-\varepsilon_{a^{N}, t}-\gamma x_{t} \\
m c_{N, t}^{*}=\left(1-\eta^{*}\right) w_{t}^{*}+\eta^{*} r_{t}^{k *}-\varepsilon_{a^{N}, t}^{*}-\gamma^{*} x_{t}^{*}
\end{gathered}
$$

Relative price of nontradable consumption goods

$$
\begin{aligned}
& \Delta x_{t}=\pi_{N, t}-\pi_{T, t} \\
& \Delta x_{t}^{*}=\pi_{N, t}^{*}-\pi_{T, t}^{*}
\end{aligned}
$$

Inflation of tradable consumption goods

$$
\begin{gathered}
\pi_{T, t}=\frac{1}{1+\omega}\left(\pi_{H, t}+(1-\alpha) \Delta s_{t}+\omega \pi_{N, t}\right) \\
\pi_{T, t}^{*}=\frac{1}{1+\omega^{*}}\left(\pi_{F, t}^{*}-\alpha^{*} \Delta s_{t}+\omega^{*} \pi_{N, t}^{*}\right)
\end{gathered}
$$

CPI inflation

$$
\begin{gathered}
\pi_{t}=\gamma \pi_{T, t}-(1-\gamma) \pi_{N, t} \\
\pi_{t}^{*}=\gamma^{*} \pi_{T, t}^{*}-\left(1-\gamma^{*}\right) \pi_{N, t}^{*}
\end{gathered}
$$

Real exchange rate

$$
q_{t}=\left(\alpha-\alpha^{*}\right) s_{t}+\left(1+\omega^{*}-\gamma^{*}\right) x_{t}^{*}-(1+\omega-\gamma) x_{t}
$$

Monetary policy rules

$$
r_{t}=\rho r_{t-1}+(1-\rho)\left(\phi_{y} y_{t}+\phi_{\pi} \pi_{t}\right)+\varepsilon_{m, t}
$$




$$
r_{t}^{*}=\rho^{*} r_{t-1}^{*}+\left(1-\rho^{*}\right)\left(\phi_{y}^{*} y_{t}^{*}+\phi_{\pi}^{*} \pi_{t}^{*}\right)+\varepsilon_{m, t}^{*}
$$

Productivity shocks in tradable sectors

$$
\begin{gathered}
\varepsilon_{a^{H}, t}=\rho_{a^{H}} \varepsilon_{a^{H}, t-1}+\mu_{a^{H}, t} \\
\varepsilon_{a^{F}, t}^{*}=\rho_{a^{F}}^{*} \varepsilon_{a^{F}, t-1}^{*}+\mu_{a^{F}, t}^{*}
\end{gathered}
$$

Productivity shocks in nontradable sectors

$$
\begin{aligned}
& \varepsilon_{a^{N}, t}=\rho_{a^{N}} \varepsilon_{a^{N}, t-1}+\mu_{a^{N}, t} \\
& \varepsilon_{a^{N}, t}^{*}=\rho_{a^{N}}^{*} \varepsilon_{a^{N}, t-1}^{*}+\mu_{a^{N}, t}^{*}
\end{aligned}
$$

Consumption preference shocks

$$
\begin{aligned}
& \varepsilon_{d, t}=\rho_{d} \varepsilon_{d, t-1}+\mu_{d, t} \\
& \varepsilon_{d, t}^{*}=\rho_{d}^{*} \varepsilon_{d, t-1}^{*}+\mu_{d, t}^{*}
\end{aligned}
$$

Labour supply shocks

$$
\begin{aligned}
& \varepsilon_{l, t}=\rho_{l} \varepsilon_{l, t-1}+\mu_{l, t} \\
& \varepsilon_{l, t}^{*}=\rho_{l}^{*} \varepsilon_{l, t-1}^{*}+\mu_{l, t}^{*}
\end{aligned}
$$

Government spending shocks

$$
\begin{aligned}
& \varepsilon_{g, t}=\rho_{g} \varepsilon_{g, t-1}+\mu_{g, t} \\
& \varepsilon_{g, t}^{*}=\rho_{g}^{*} \varepsilon_{g, t-1}^{*}+\mu_{g, t}^{*}
\end{aligned}
$$

Investment efficiency shocks

$$
\begin{aligned}
& \varepsilon_{i, t}=\rho_{i} \varepsilon_{i, t-1}+\mu_{i, t} \\
& \varepsilon_{i, t}^{*}=\rho_{i}^{*} \varepsilon_{i, t-1}^{*}+\mu_{i, t}^{*}
\end{aligned}
$$

Monetary shocks

$$
\begin{aligned}
& \varepsilon_{m, t} \\
& \varepsilon_{m, t}^{*}
\end{aligned}
$$

Vectors of stochastic disturbances:

$$
u_{t}=\left[u_{i, t}\right]=\left[\begin{array}{lllllll}
\mu_{a^{H}, t} & \mu_{a^{N}, t} & \mu_{d, t} & \mu_{l, t} & \mu_{g, t} & \mu_{i, t} & \varepsilon_{m, t}
\end{array}\right]
$$




$$
u_{t}^{*}=\left[u_{i, t}^{*}\right]=\left[\begin{array}{lllllll}
\mu_{a^{F}, t}^{*} & \mu_{a^{N}, t}^{*} & \mu_{d, t}^{*} & \mu_{l, t}^{*} & \mu_{g, t}^{*} & \mu_{i, t}^{*} & \varepsilon_{m, t}^{*}
\end{array}\right]
$$

with:

$$
\begin{gathered}
E\left[u_{i, t}\right]=E\left[u_{i, t}^{*}\right]=0 \\
E\left[u_{i, t} u_{i, t}\right]=\sigma_{i}^{2} \quad E\left[u_{i, t}^{*} u_{i, t}^{*}\right]=\sigma_{i}^{* 2} \\
E\left[u_{i, t} u_{i, t}^{*}\right]=\operatorname{corr}_{i} \sigma_{i} \sigma_{i}^{*}
\end{gathered}
$$

